\title{
THE ROLES OF ACADEMIC INVENTORS IN MEDICAL INNOVATION PROCESSES: EXPLORING THE INFLUENCE OF IPR OWNERSHIP AND IP NATURE
}

\author{
ANDERS BRANTNELL* \\ Department of Women's and Children's Health \\ Uppsala University, Sweden \\ anders.brantnell@kbh.uu.se \\ ENRICO BARALDI \\ Department of Engineering Sciences \\ Uppsala University, Sweden
}

Published 2 August 2019

\begin{abstract}
This paper analyses four medical innovation processes originating from Stanford and Uppsala universities with the purpose of understanding how intellectual property rights (IPR) ownership and intellectual property (IP) nature influence the behaviour of academic inventors. We analyse this behaviour through the roles enacted and evaluate the requirements the roles pose by developing a method to assess the requirements of individual roles, which we label as role intensity. We find that both IPR ownership and IP nature can influence the academic inventors' roles and role intensities. In contrast to assumptions in research and policy, we find that IPR ownership does not influence the roles and role intensities in a remarkable way. We also find support that research and policy should distinguish between patentable and non-patentable inventions in the field of medical invention as these two types of IP nature are associated with different roles and role intensities. These findings contribute to the literature on commercialisation of science and innovation management by demonstrating the importance of IP nature in influencing the roles of inventors. Managerial and policy implications are provided.
\end{abstract}

Keywords: Science commercialisation; intellectual property rights; university ownership; inventor ownership; patent; medical innovation.

${ }^{*}$ Corresponding author.

This is an Open Access article published by World Scientific Publishing Company. It is distributed under the terms of the Creative Commons Attribution 4.0 (CC BY) License which permits use, distribution and reproduction in any medium, provided the original work is properly cited. 


\section{Introduction}

Universities are claimed to be the engines of economic development by creating inventions that can be commercialised and thereby contributing to economic development and welfare (Etzkowitz and Leydesdorff, 2000; OECD, 2003; Wright et al., 2008). In this context, the role of the academic researcher expands from conducting research, teaching and leading research projects to playing key roles for innovations (Kidwell, 2014; Mangematin et al., 2014; Cunningham et al., 2016). More precisely, academic researchers become academic inventors and entrepreneurs. Such expansion of the academic's role brings along new tasks, such as involvement in technology transfer, licensing and patenting (Mangematin et al., 2014), which puts new requirements on academics. Previous studies on academic inventors have demonstrated that academic inventors' involvement is central for successful outcomes (Friedman and Silberman, 2003; Clarysse and Moray, 2004; Markman et al., 2005; Hayter, 2011).

In particular, the outcomes of academic entrepreneurship that research and policy traditionally consider are patenting, licensing and starting a spinoff company to commercialise academic inventions (Boehm and Hogan, 2014; Jensen and Thursby, 2001; Klofsten and Jones-Evans, 2000; Mangematin et al., 2014; Murray, 2004; Thorburn, 2000; Thursby et al., 2001; Zucker et al., 2002). To explain these outcomes, scholars have focused on several factors concerning individual academic inventors such as their gender (Azoulay et al., 2007), organisational factors such as peer pressure (Bercovitz and Feldman, 2008) and broader institutional factors such as the ownership of inventions (Kenney and Patton, 2011). Based on these and other studies, we know that there is a multitude of factors that influence academic inventors' behaviour and its outcomes (i.e., patenting, licensing and starting a spinoff company). However, there are two limitations to these studies. A first issue is that the temporal scope of the existing studies is rather narrow because the patenting, licensing and starting a spinoff company do not cover the whole innovation process (Van de Ven et al., 1999). During an innovation process, inventions are invented, protected, developed, brought to market and used by the general public (Attridge, 2007; Van de Ven et al., 1999), and thus focusing solely on patenting, licensing and starting a spinoff company does not provide the whole picture.

A second issue in existing research on academic inventors' behaviour is the diverging results and limited understanding concerning institutional factors. One of them is intellectual property rights (IPR) ownership, referring to who owns the university research results: for instance, some studies show that inventor ownership (a system whereby inventors own the research results) provides solid incentives for academic inventors (Kenney and Patton, 2011; Lindelöf, 2011; 
Litan et al., 2008; Mowery et al., 2001), whereas others show that university ownership (a system in which universities own the research results) provides more incentives for inventors than inventor ownership (Farnstrand Damsgaard and Thursby, 2013; Goldfarb and Henrekson, 2003; OECD, 2003). Other researchers in turn find evidence that increased patenting and licensing is not connected to university ownership, but that such development would have taken place independently from university ownership (Mowery and Sampat, 2005). Despite its unclear outcomes and benefits, many countries have established university ownership, such as Denmark, Finland, Austria, Japan, Germany and Norway (Geuna and Rossi, 2011; Rasmussen et al., 2006), and other countries, such as Sweden, consider whether they should do that (Farnstrand Damsgaard and Thursby, 2013). Consequently, IPR ownership and its influence on academic inventors' behaviour are interesting both from a research and from a policy perspective.

Another institutional factor that can influence academic inventors' behaviour is the nature of intellectual property (IP), referring to whether or not the invention can be patented or not. Drafting a theory on patentability, Arrow (1962) argues that patenting is needed for the inventor to be able to reveal their invention and still earn profits on that. In line with this theory, many studies have confirmed the incentives that patentable inventions create for inventors (Azoulay et al., 2007; Clancy and Moschini, 2013); especially in the field of medical research, in which patentability is viewed as one of the cornerstones for commercial exploitation (Colyvas et al., 2002; Garber et al., 2006). However, medical research is much broader including important inventions that cannot be patented, for instance, in the area of self-management of diseases (Titov, 2007). Little is known about which incentives these kinds of non-patentable inventions (inventions that cannot be patented) provide for academic inventors and how such inventions find their ways to commercial exploitation. However, in line with Arrow's (1962) theory, Anton and Yao (1994) argue that inventions that are not protected by patents decrease the chances of earning profits. These inventions can be protected through other means such as copyrights and trademarks (Arora and Gambardella, 2010; Herstatt and von Hippel, 1992), but this kind of protection is not assumed to provide strong juridical protection as in Arrow's (1962) theory on patenting, which decreases the chances of earning profits and thus lowers inventor involvement. Consequently, patentable IP can be assumed to provide more incentives for inventors' involvement than non-patentable IP. However, the impact of IP nature on academic inventors' behaviour, especially in the medical field, is tenuous and not well understood. In line with these issues, recent reviews call for more studies concerning the influence of institutional factors on academic inventors' behaviour (Djokovic and Souitaris, 2008; Rothaermel et al., 2007). 
To address the two limitations described earlier (i.e., focus on only parts of the innovation process and lack of clarity concerning institutional factors' influence on academic inventors behaviour), the purpose of this paper is to examine the roles of academic inventors during the entire innovation process and identify how IPR ownership and IP nature might influence these roles. We studied four medical innovation processes characterised by different combinations of IPR ownership and IP nature. Originating from Stanford (US) and Uppsala (Sweden) universities, respectively, the innovations selected had all progressed from discovery to use in medical practice, representing new medical treatments in the market.

Our findings indicate that IPR ownership and especially IP nature can influence the roles of academic inventors in particular ways. Thus, this paper contributes to the literature on commercialisation of science and innovation management by highlighting the effect of IPR ownership and especially of IP nature, which is a less explored factor. Further, this study complements the literature by identifying several roles of academic inventors and providing a deeper understanding of them. The paper is organised as follows: after reviewing factors influencing academic inventors behaviour, we present our methodology. This is followed by the results from the four cases, which are analysed in a dedicated discussion section. The paper ends with policy and managerial implications.

\section{Literature Review}

Academic inventors' behaviour has received a lot of interest in previous research and the factors identified to influence academic inventors behaviour can be divided into three streams: (1) individual, (2) organisational and (3) institutional factors. Next, we will review the research concerning these three factors with a focus on institutional ones.

\section{Individual factors influencing academic inventors' behaviour}

In the first stream, many studies have focused on the number of publications and publishing behaviour of academics, finding that the number of publications is positively connected to patenting and number of patents (Azoulay et al., 2007; Breschi et al., 2007; Carayol, 2007; Stephan et al., 2007; Van Looy et al., 2006; Zucker et al., 2002). However, Gulbrandsen and Smeby (2005) report, based on their survey among all tenured Norwegian professors, that the number of publications does not increase with the number of patents. Another sizeable factor in the first stream concerns gender. Here researchers have found that there is a gender gap in patenting as women patent less than their male colleagues 
(Azoulay et al., 2007; Ding et al., 2006; Gulbrandsen and Smeby, 2005; Stephan et al., 2007). Azoulay et al. (2007) and Ding et al. (2006) also provided numbers for this gap, showing that women patent $40-50 \%$ less than males do. Also industry factors such as industry experience (Dietz and Bozeman, 2005), industry ties (Gulbrandsen and Smeby, 2005; Krabel and Mueller, 2009; Owen-Smith and Powell, 2001; Stuart and Ding, 2006) and industry funding (Gulbrandsen and Smeby, 2005) are related to increased patenting and commercialisation of research output. Age as a factor has received interest, but the findings are not univocal as Azoulay et al. (2007) report that mid-career academics patent more than younger and older academics, whereas Carayol (2007) found that patenting is more likely among older academics. Gulbrandsen and Smeby (2005), in turn, found no influence of age on commercialisation of research output. Finally, Ding et al. (2006) found that younger women who were patenting viewed it in the same way as their male counterparts. In addition to the above-described four broad themes, several other factors have received interest within the individual factors stream, such as opportunities (Azoulay et al., 2007), study background (Bercovitz and Feldman, 2008), entrepreneurial experience (Clarysse et al., 2011), view on commercialisation (Krabel and Mueller, 2009) and years from PhD (Stephan et al., 2007). In conclusion, studies on individual factors in general measure patenting as the predominant form of behaviour and connect it with different individual factors.

\section{Organisational factors influencing behaviour}

In the second stream, patenting experience of the department (Azoulay et al., 2007; Stephan et al., 2007) or the previous patenting experience of the department chair (Bercovitz and Feldman, 2008) was found to increase patenting. Azoulay et al. (2007) and Bercovitz and Feldman (2008) noticed that there was a peer effect in patenting, meaning that academic inventors were more likely to patent if their department colleagues did so. Other than previous experience in patenting and peer effect in patenting, the other organisational factors entail quite varied effects. For instance, Siegel et al. (2003) found that university bureaucracy was perceived as a barrier to licensing. Lockett and Wright (2005) found that the Technology Transfer Office's (TTO's) business skills were related positively to starting companies, and Carayol (2007) noticed that lab size and lab funds were related positively to increased patenting. In conclusion, many of the studies concerning the organisational factors measure patenting and starting a spinoff company as the predominant form of behaviour and connect these outcomes with different organisational factors. 


\section{Institutional factors influencing behaviour}

In the third stream, studies have revolved around different incentives that influence academic inventors' behaviour. One sizeable incentive that is found to influence starting a spinoff company is the IPR ownership structure (Haeussler and Colyvas, 2011; Crespi et al., 2006; Grimpe and Fier, 2010; Goldfarb and Henrekson, 2003; Farnstrand Damsgaard and Thursby, 2013; Kenney and Patton, 2011). In general, two different structures are studied - university and inventor ownership — but the conclusions diverge concerning the influence of ownership structures. In its essence, the IPR ownership question materialises one fundamental underlying aspect, namely, the issue of profit sharing. In inventor ownership, the profits from technology transfer are harvested solely by the academic inventor, whereas in university ownership the profits are shared between different parties (e.g., inventor, faculty and TTO) (Goldfarb and Henrekson, 2003; Thursby and Thursby, 2007).

Another institutional factor found to influence academic inventors' behaviour is the patentability of the invention (Azoulay et al., 2007; Thursby and Thursby, 2007), labelled here as the IP nature. In such studies, the advantages of patentable inventions in involving academic inventors are highlighted (Azoulay et al., 2007; Clancy and Moschini, 2013; Hellmann, 2007; Murray and Stern, 2007; Scotchmer, 2004; Thursby and Thursby, 2007). However, patentable inventions are seldom compared with non-patentable inventions, which are thus either assumed to be less important than patentable inventions or similar to patentable inventions. Consequently, the existing studies do not investigate how the patentable or non-patentable nature of inventions influences academic inventors' behaviour. In its essence, the IP nature question materialises one fundamental underlying aspect, namely, the issue of profit-making. Patentable inventions are assumed to provide higher income to academic inventors as the value of inventions is visible and codified (Clancy and Moschini, 2013).

To sum up, studies on institutional factors influencing inventors' behaviour have mainly revolved around IPR ownership, but as indicated earlier these studies do not provide clear conclusions on how the different types of IPR ownership structures affect inventor behaviours and which specific roles they can shape. There are many studies showing the advantages of patentable inventions, but few studies that compare inventions with different IP nature. In line with these gaps, two reviews (Djokovic and Souitaris, 2008; Rothaermel et al., 2007) call for more studies focusing on the incentive structures that influence academic inventors' behaviour. Next, we will briefly review the literature concerning IPR ownership and IP nature, which impinge on the two incentive factors explored in this paper. 


\section{IPR ownership and the behaviour of academic inventors}

IPR ownership can be divided into two basic structures: ${ }^{1}$ one in which the university owns the IPR generated by public funds and another in which the scientist, that is, the inventor, owns the IPR, a system known as the "professor's privilege" (Geuna and Rossi, 2011). Previous research has compared both different and similar IPR ownership structures (Crespi et al., 2006; Goldfarb and Henrekson, 2003; Farnstrand Damsgaard and Thursby, 2013; Kenney and Patton, 2011). Goldfarb and Henrekson (2003) suggest that university ownership provides incentives for inventors to be involved despite lack of total control, usually through a share of future royalties, whereas in inventor ownership, the opportunity costs of conducting all innovation activities alone create a disincentive for inventor involvement. However, Kenney and Patton (2011), who compared six North American universities, found that inventor ownership encourages spinoff creation by academic inventors. Farnstrand Damsgaard and Thursby (2013) suggest that the higher occurrence of spinoff creation in inventor ownership depends on the fact that the inventor gets a larger share of incomes than in university ownership. However, in line with Goldfarb and Henrekson (2003), also Farnstrand Damsgaard and Thursby (2013) acknowledge that technology transfer success is more probable in university ownership structures, where inventors' typically limited commercialisation skills are counterbalanced by the intervention of TTOs. Moreover, Crespi et al. (2006) found that the university ownership model is not superior to the inventor ownership model in providing incentives to patent.

Further, others also found support that the assumed positive effects of university ownership are not based solely on the merits of university ownership (Kenney and Patton, 2009; Litan et al., 2008; Mowery and Sampat, 2005; Powell et al., 2007). Powell et al. (2007) argue that the reform — the Bayh Dole Act (BDA) - that transferred ownership to US universities has not improved technology transfer and the use of existing IP. In line with this, Mowery and Sampat (2005) state that the increase in patenting and licensing in the US followed a suggested development curve, implying that increase in patenting and licensing would have taken place even without the BDA. Kenney and Patton (2012), in turn, illustrate how the growth of such fields as biotechnology pushed the need to patent and license in the 1980s.

\footnotetext{
${ }^{1}$ In both structures, the inventor is the researcher and the IPR emerging from publicly funded research is owned either by the university or the inventor. However, if research is funded by private means, for instance, by a company, the company might claim the rights to IP and become the IPR owner. If the company owns the IPR, technology transfer does not take place in a similar way as when a university-based actor owns the IPR.
} 
Studies focusing on countries which have recently introduced university ownership even suggest that the new ownership structure might be counterproductive for commercialisation or have no effect (Geuna and Rossi, 2011; Lissoni et al., 2009; von Proff et al., 2012). All in all, previous research on the advantages and disadvantages of different IPR ownership structures does not lead to conclusive and decisive evidence on whether and in which way the different IPR ownership models provide, contrary to beliefs in policy circles (Merrill and Mazza, 2011; OECD, 2003), clear incentives to academic inventors and thereby how they affect their behaviour in innovation processes.

\section{IP nature and the behaviour of academic inventors}

Arrow (1962) argues that in technology licensing the company wishing to license an invention is interested to know the nature of the invention before licensing-in. However, if the invention is not protected, the inventor would lack incentives to reveal the invention because once it is revealed, the company would not pay for it. According to Arrow (1962), the solution to this dilemma was patenting, which would protect the inventor and still provide incentives for the potential licensees. In conclusion, the inventor possessing a patentable invention could sell this to third parties and thus earn profits. In line with Arrow's (1962) theory on patentability of university inventions, academic inventors can be assumed to be more interested about patentable IP, and indeed patentability has been shown to be a good predictor of academic inventor involvement (Azoulay et al., 2007; Clancy and Moschini, 2013; Hellmann, 2007; Murray, 2004; Thursby and Thursby, 2007). Clancy and Moschini (2013) develop a theoretical framework in which they show that patents once granted become a legally sanctioned property. Such property in turn gives exclusivity to the inventor owning the patent, who can obtain consequently larger profits. Clancy and Moschini (2013) argue that such exclusivity can be a sizeable incentive to develop patentable inventions. Thursby and Thursby (2007) conducted surveys with university licensing professionals and business licensing professionals in the US and found that patenting in general provides a solid incentive for academic inventors, for instance, they found that $71 \%$ of academic inventors were involved in further development of their inventions.

Some findings also indicate that the importance of patents may be dependent on the context (Artz et al., 2010) or the sector (Willoughby, 2013), implying that patents are more important for some context or sectors. Indeed, the impact of patentability is especially highlighted in medical research where patentable IP is viewed as a requirement for commercial exploitation (Colyvas et al., 2002; Garber et al., 2006; Pressman et al., 2006; Smith Hughes, 2001). Colyvas et al. (2002) studied a sample of inventions such as a new treatment for eye disease (not all of 
them medical inventions though) from Stanford and Columbia universities and noticed that in this sample the inventions that needed considerable development into commercial products benefitted most from patents (Colyvas et al., 2002). Pressman et al. (2006), in turn, report on the patenting of DNA inventions based on their survey from 19 US universities, showing that $70 \%$ of the 2670 patents owned by the 19 universities were either licensed or had been licensed. Based on Pressman et al. (2006), patentability can thus be seen as a condition for commercialisation of DNA inventions. However, medical research aims to solve complex problems and gives rise to a broad array of inventions (Atun and Sheridan, 2007) including important medical innovations that cannot be protected through patents (here labelled as non-patentable IP), such as various selfmanagement programs provided through internet (Lorig et al., 2006, 2008; Zetterqvist et al., 2003; Andersson et al., 2005) or face-to-face (Lorig et al., 2014; Kennedy et al., 2007; LeFort et al., 1998). Currently, little is known about incentives that non-patentable medical inventions provide for academic inventors and thus how they influence inventors' behaviour.

All in all, both IPR ownership and IP nature provide incentives for inventor involvement, but at the moment their impact is not well understood. Moreover, when compared with the individual and organisational level factors influencing inventor behaviour, the incentive structures of IPR ownership and IP nature seem to be the ones that most deserve further studies. Despite the focus of this paper on IRP ownership and IP nature, we do not claim that these two factors influence the most the behaviour of academic inventors, because there are several other factors, such as gender or age of the academic inventor or peer patenting, which may do so. We simply aim to compare these two incentive structures and explore their possible influence on inventors' behaviour.

\section{Methods}

\section{Research design}

Our point of departure was studying how IPR ownership and IP nature play out in innovation processes originating from universities. After the first streams of data collection and an initial empirical analysis, our focus was directed towards the behaviour of academic inventors when facing different IPR ownership structures and IP natures. Knowledge on these specific issues appeared scattered and the phenomenon studied was complex enough to require a qualitative in-depth methodology, rather than formal hypothesis testing. Therefore, we followed a multiple case study approach based on four cases which were selected through theoretical sampling (Eisenhardt, 1989; Yin, 2003). 
More precisely, first, we selected cases representing two different IPR ownership structures and academic contexts (Stanford, with university ownership, and Uppsala, with inventor ownership) in order to capture possible variations in the influence of different IPR ownership structures on academic inventors behaviour. Secondly, we selected cases that provided variation concerning IP nature (two cases with patentable IP and two cases with non-patentable IP). assuming that patentable and non-patentable IP could influence the behaviour of academic inventors in different ways. Thus, the resulting sample comprises: one case with patentable IP owned by the university (Alpha as presented in our Findings), one case with non-patentable IP owned by the university (Beta), one case with patentable IP owned by the inventor (Gamma) and one case with non-patentable IP owned by the inventor (Delta). All these inventions were created by university researchers and the local law was used to interpret whether or not the cases where university spinoff. For instance, Delta was founded by a $\mathrm{PhD}$ student who did not involve the innovation support office in the commercialisation. In Sweden, $\mathrm{PhD}$ students employed by universities own their research results and can decide whether or not to involve the innovation support office, exactly like other academic inventors belonging to the permanent faculty. Thirdly, in order to capture the whole innovation process (Van de Ven et al., 1999), we selected cases in which the inventions had all been transformed into usable products in the market. In order to identify innovations that would satisfy our inclusion criteria, we reviewed homepages, databases and talked with stakeholders in the selected universities. In addition to this, we also reviewed the Stanford OTL annual reports from 2000 to 2008 .

\section{Data collection}

Data triangulation consisting of several sources of data was used to build a precise picture of the four innovation journeys (Van de Ven et al., 1999) and the behaviour of inventors during these processes. The main source of data came from stakeholder interviews but the interviews were combined with secondary data from databases that displayed the financial information for the cases and with data from company documents and homepages. Both countries were visited in order to conduct interviews with different stakeholders that consisted of academic inventors, primary company founders, various innovation supporting actors, key users and other supporting actors such as NGOs. Altogether, 38 respondents were interviewed (the majority of them face-to-face) for between $30 \mathrm{~min}$ and $90 \mathrm{~min}$. In addition to interviews, some additional and complementary information was obtained through e-mail communication. Furthermore, adhering to snowballing techniques, we asked every respondent to propose other relevant persons to 
interview who could elucidate the innovation process and/or had been involved in the process (Patton, 2002). Grounding on data saturation, we conducted new interviews as long as new data continued emerging (Yin, 2003). In order to facilitate for comparison of the four cases similar interview guides were used as a starting point, but adapted for each respondent, with the possibility to delve deeper into certain aspects through follow-up questions. The questions had to do with the innovation process, the actors that had been involved and their behaviour in the process, possible obstacles that were encountered during the process and facilitating factors that could explain the innovation process outcome. The data collection took five months in Stanford in 2013 and nine months in Uppsala between 2014 and 2015, respectively.

\section{Data analysis}

The verbatim-transcribed empirical material was reviewed and checked for accuracy. Based on the empirical material, four case histories were constructed. The case histories were validated by the respondents. The four case histories were together 19,930 words in length. After this, the analysis process was divided into five phases: First, we started scanning the case histories in search for clues of how IPR ownership and IP nature influenced the behaviour of inventors. We noticed that the academic inventors behaved in different ways and were undertaking different roles during the innovation process. Roles as such have been understood in different ways in previous research: some roles rely on a specific competence of the inventor, which is needed during the innovation journey, such as the technical knowledge of the technical consultant (Jensen and Thursby, 2001). Other roles rely on a certain position held by the inventor during the innovation journey in relation to the invention, such as company founder (Haeussler and Colyvas, 2011), whereas others rely on a certain activity that has to be carried out, such as brokering (Boehm and Hogan, 2014). Moreover, a role such as brokering partly includes a practical activity but also requires a certain competence to be performed. Consequently, extant research has, albeit implicitly, considered the roles of academic inventors in three different ways: as competences, positions and activities.

Irrespective of these implicit definitions of what constitutes a role, they all tap into important steps in innovation processes and can thus be distinguished from idiosyncratic practices or micro-practices that describe the more mundane behaviour of individuals, such as attending a sports event, disciplining a client or reviewing figures (Rouleau, 2005; Smets et al., 2015). Inspired also by Van de Ven et al. (1999) and their notion of an innovation journey, we define academic inventor roles as sustained and repeated behaviours which in various ways 
support the progress of an invention through the innovation process and its various periods, from the emergence of an innovative idea until its adoption and actual use.

Secondly, we conducted a content analysis of the empirical material in order to identify the inventor roles within cases (Eisenhardt, 1989) expressed through their competences, positions and actions. Thirdly, we matched the roles with the case histories and drafted shorter case histories centered on the roles of inventors. These four narratives are presented in the findings section. Fourth, we re-analysed the case histories, in order to understand the scope and requirements of individual roles. We labelled such requirements as role intensity. In order to ground the operationalisation of intensity, we consulted the existing literature on involvement with a focus on user involvement/participation in the design of new technology (Alam, 2002; Barki and Hartwick, 1994; Ives and Olson, 1984) and noticed that the existing literature raises "extent" and "time" as important factors in measuring participation/involvement (Doll and Torkzadeh, 1989; Franz and Robey, 1986; Robey et al., 1989). More precisely, we assessed role intensity using two indicators: the "degree" (i.e., the amount of time or effort required to carry out a specific role) and the "duration" (i.e., how often a specific role was carried out) of each role, with three possible levels of role intensity - low, medium and high intensity. The role's "degree" consisted of three alternatives: (1) "one task among others" (coded as 1), (2) equivalent to "part-time employment" (coded as 2) and (3) equivalent to "full-time employment" (coded as 3). Also the role "duration" could vary between three alternatives: (1) "once" (coded as 1), (2) "several times" (coded as 2) and (3) "continuously" (coded as 3). Based on this coding, we estimated the intensity of each role based on the sum of the values of the "degree" and "duration" of a role. To this end, an individual role with a sum of "degree" and "duration" of 2-3 was defined as a low-intensity role, a role with a sum of 4-5 was defined as a medium-intensity role and finally a role with a sum of 6 was defined as a high-intensity role (see Table 1 after the case studies for a complete overview of our assessment and numerical coding).

Finally, we conducted a cross-case comparison (Eisenhardt, 1989) of the roles and their intensities in the four innovations tracing patterns in the connections between academic inventor roles and role intensities concerning IPR ownership and IP nature.

\section{Findings}

This section features the four case histories starting from the two innovation processes originating from Stanford University and then moving on to the two 
cases from Uppsala University. The case histories illuminate what the inventors did, the corresponding roles and the intensity of each role. Each role is supported by a quote when it first appears except two of the roles: spinoff founder and spinoff shareholder that are self-explanatory. In addition, some of the roles and intensities that are already mentioned in previous cases are supported by additional quotes.

\section{Alpha from Stanford University (patentable IP owned by the university)}

The idea that laid the foundations of the innovation known as Alpha ${ }^{2}$ was initiated in 1995 by Researcher A when he was employed at University X and started to investigate whether pulsed plasma could be created by electrical means to enable the production of inexpensive medical lasers. The first device developed was microscopic in size and had little practical value. Researcher A arrived to Stanford in 1996 and started collaboration with Department Y in 1999 where the Head of Department, Dr. C, told Researcher A that an inexpensive solution and more precise device was needed for eye surgery. Researcher A, as the principal investigator (PI), received federal funding to start to develop a new device and hired another researcher who became the co-inventor of the device. The PI disclosed Alpha to the Stanford Office of Technology Licensing (OTL) in 2000 and consequently assumed the role of discloser:

"I mean we disclosed to OTL [the TTO], so they know. We disclosed to them." (PI Alpha)

This role constituted one task among others and took place once, which makes this a low-intensity role (see Table 1 for details on role intensities in each of the four cases and Table 2 for details on roles in the four cases). Following the disclosure, the OTL and the inventors worked together to define the IP and undertook a complex set of actions forming the role of IP co-drafter:

\section{"Then he [the TTO rep] wrote the IP, then I just edited this IP, and then X [the PI] edited the IP. It's the normal process." (Co-inventor Alpha)}

This role was one task among others but took place several times preceding the patent application and also afterwards, as will be shown below, which makes it a low-intensity role. After the IP was defined and protected, the PI

\footnotetext{
${ }^{2}$ All the four case names and the names and titles of the actors involved are masked to protect the identity of the respondents.
} 
Table 1. Roles and role intensity.

\begin{tabular}{|c|c|c|c|}
\hline & $\begin{array}{c}\text { Degree: one task among } \\
\text { others (OTAO), part-time } \\
\text { employment (PTE), } \\
\text { full-time employment (FTE) }\end{array}$ & $\begin{array}{l}\text { Duration: once }(\mathrm{OT}) \text {, } \\
\text { several times }(\mathrm{ST}), \\
\text { continuously }(\mathrm{C})^{\mathrm{b}}\end{array}$ & $\begin{array}{l}\text { Role intensity: } \\
\text { low, medium, } \\
\text { high }^{c}\end{array}$ \\
\hline \multicolumn{4}{|l|}{ Alpha roles } \\
\hline 1. Discloser & OTAO (1) & OT (1) & Low (2) \\
\hline 2. IP co-drafter & OTAO (1) & ST (2) & Low (3) \\
\hline 3. Technology transfer driver & OTAO (1) & ST (2) & Low (3) \\
\hline 4. Broker & OTAO (1) & ST (2) & Low (3) \\
\hline 5. Spinoff founder & OTAO (1) & OT (1) & Low (2) \\
\hline 6. Spinoff shareholder & OTAO (1) & $\mathrm{C}(3)$ & Medium (4) \\
\hline 7. Technology developer & FTE (3) & $\mathrm{C}(3)$ & High (6) \\
\hline 8. Knowledge carrier & FTE (3) & C (3) & High (6) \\
\hline 9. Technical consultant & OTAO (1) & ST (2) & Low (3) \\
\hline 10. Technology validator & OTAO (1) & ST (2) & Low (3) \\
\hline 11. Furthering research & FTE (3) & C (3) & High (6) \\
\hline \multicolumn{4}{|l|}{ Beta roles } \\
\hline 1. Discloser & OTAO (1) & OT (1) & Low (2) \\
\hline 2. Technology transfer driver & FTE (3) & ST (2) & Medium (5) \\
\hline 3. Licensing manager & FTE (3) & C (3) & High (6) \\
\hline 4. Technology trainer & FTE (3) & $\mathrm{C}(3)$ & High (6) \\
\hline 5. Technology promoter & FTE (3) & $\mathrm{C}(3)$ & High (6) \\
\hline 6. Adoption promoter & OTAO (1) & ST (2) & Low (3) \\
\hline 7. Evangeliser & FTE (3) & $\mathrm{C}(3)$ & High (6) \\
\hline 8. Furthering research & FTE (3) & $\mathrm{C}(3)$ & High (6) \\
\hline \multicolumn{4}{|l|}{ Gamma roles } \\
\hline 1. Technology transfer driver & OTAO (1) & ST (2) & Low (3) \\
\hline $\begin{array}{l}\text { 2. Expert in the innovation } \\
\text { supporting system }\end{array}$ & OTAO (1) & ST (2) & Low (3) \\
\hline 3. Broker & OTAO (1) & ST (2) & Low (3) \\
\hline 4. Spinoff founder & OTAO (1) & OT (1) & Low (2) \\
\hline 5. Spinoff shareholder & OTAO (1) & $\mathrm{C}(3)$ & Medium (4) \\
\hline 6. IP holder definer & OTAO (1) & OT (1) & Low (2) \\
\hline 7. Spinoff runner & FTE (3) & $\mathrm{C}(3)$ & High (6) \\
\hline 8. Technology developer & FTE (3) & C (3) & High (6) \\
\hline 9. Technology promoter & PTE (2) & $\mathrm{C}(3)$ & Medium (5) \\
\hline 10. Technology trainer & PTE (2) & C (3) & Medium (5) \\
\hline 11. Business developer & OTAO (1) & ST (2) & Low (3) \\
\hline 12. Fundraiser & OTAO (1) & ST (2) & Low (3) \\
\hline 13. IP co-drafter & OTAO (1) & ST (2) & Low (3) \\
\hline 14. Furthering research & FTE (3) & $\mathrm{C}(3)$ & High (6) \\
\hline 15. Technical consultant & OTAO (1) & ST (2) & Low (3) \\
\hline 16. Knowledge carrier & FTE (3) & $\mathrm{C}(3)$ & High (6) \\
\hline 17. Technology validator & OTAO (1) & ST (2) & Low (3) \\
\hline
\end{tabular}


Table 1. (Continued)

\begin{tabular}{lccc}
\hline & $\begin{array}{c}\text { Degree: one task among } \\
\text { others (OTAO), part-time } \\
\text { employment (PTE), } \\
\text { full-time employment (FTE) }\end{array}$ & $\begin{array}{c}\text { a } \\
\text { Duration: once (OT), } \\
\text { several times (ST), } \\
\text { continuously (C) }^{\text {b }}\end{array}$ & $\begin{array}{c}\text { low, medium, } \\
\text { high }^{\text {c }}\end{array}$ \\
\hline $\begin{array}{l}\text { Delta roles } \\
\text { 1. Technology transfer driver }\end{array}$ & FTE (3) & C (3) & High (6) \\
2. IP holder definer & OTAO (1) & OT (1) & Low (2) \\
3. Technology promoter & FTE (3) & C (3) & High (6) \\
4. Fundraiser & OTAO (1) & ST (2) & Low (3) \\
5. Spinoff founder & OTAO (1) & ST (2) & Low (3) \\
6. Spinoff shareholder & OTAO (1) & C (3) & Medium (4) \\
7. Spinoff runner & FTE (3) (3) & High (6) \\
8. Technology evaluator & OTAO (1) & ST (2) & Low (3) \\
9. Adoption promoter & OTAO (1) & ST (2) & Low (3) \\
10 Licensing manager & OTAO (1) & ST (2) & Low (3) \\
11. Evangeliser & FTE (3) & C (3) & High (6) \\
12. Technology developer & FTE (3) & C (3) & High (6) \\
\hline
\end{tabular}

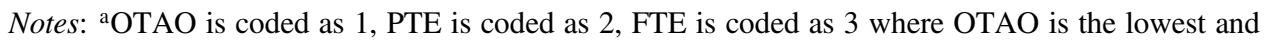
FTE is the highest. PTE and FTE indicate roles equivalent to such activities and thus should not be interpreted necessarily as a formal part- or full-time employment.

${ }^{\mathrm{b}} \mathrm{OT}$ is coded as $1, \mathrm{ST}$ is coded as $2, \mathrm{C}$ is coded as 3 , where OT is the lowest and $\mathrm{C}$ is the highest. "We have calculated the intensity of each role by adding the numbers (1-3) from the columns "degree" and "duration" together: 2-3 corresponds to "low," 4-5 to "medium" and 6 to "high."

started to push for utilisation of the IP, a role that we labelled as a technology transfer driver:

"All I wanted is just don't interfere, let me run the show, because I don't expect people to know more than me in my field. If you just don't interfere, let me establish all the contacts." (PI Alpha)

When undertaking this role, the PI connected the inventors with Company X, a role that we defined as the broker:

"We [the PI and the co-inventor] identified the company that licensed the technology." (PI Alpha)

This brokering resulted in a collaborative effort that aimed to develop Alpha for use in eye surgery. Both the technology transfer driver and the broker roles were tasks among others for the inventors. Even if they took place several times (as will be shown subsequently), they both remain low-intensity roles. 


\section{A. Brantnell \& E. Baraldi}

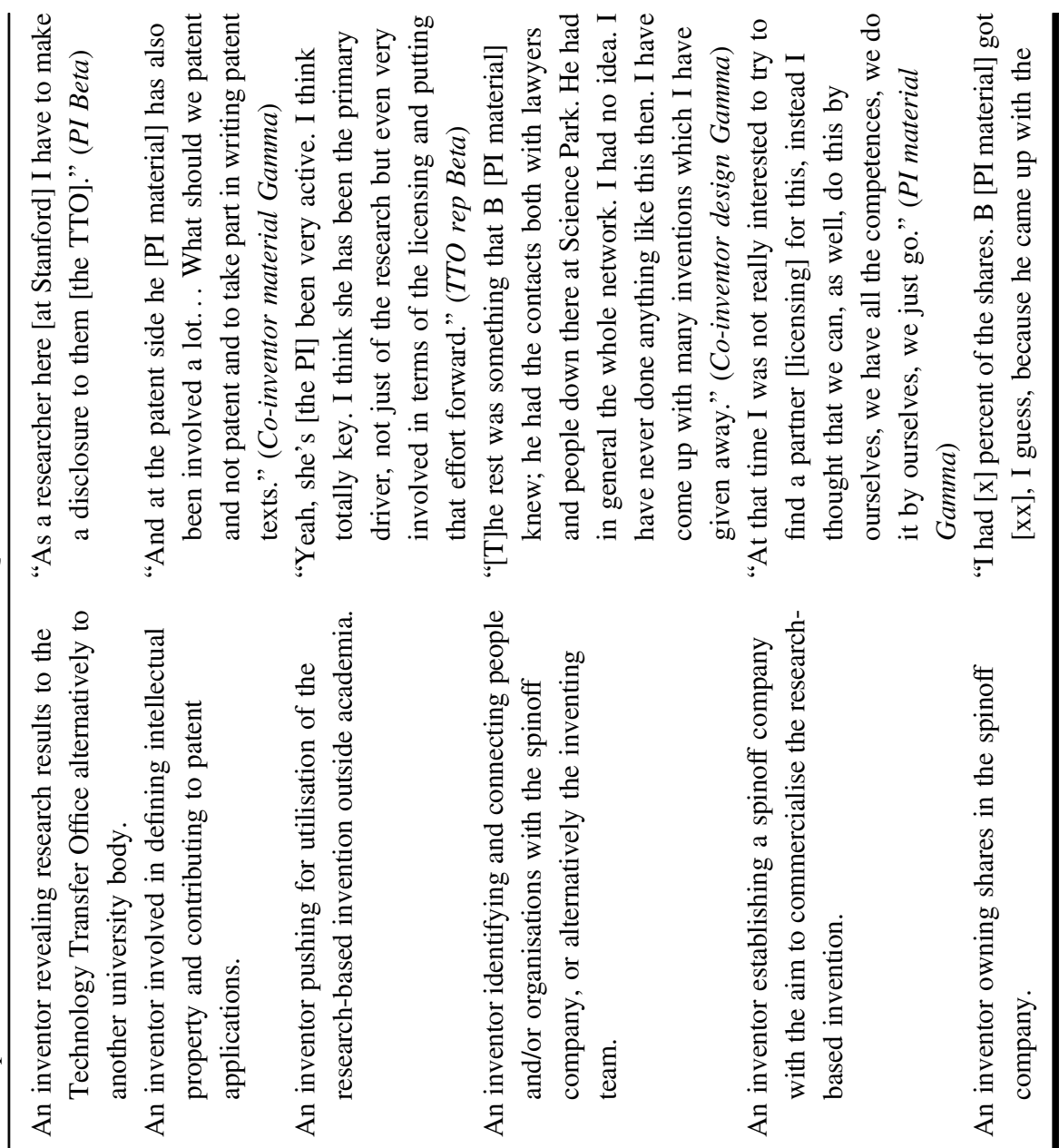

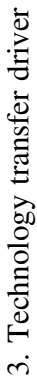

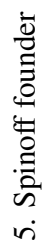

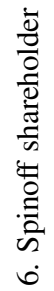




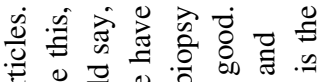

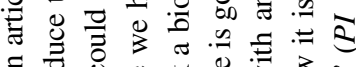
ธิ

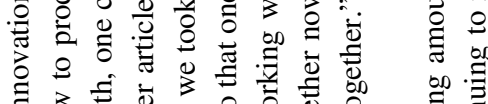

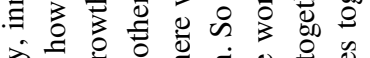

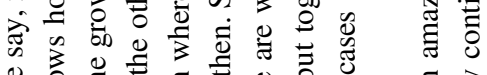

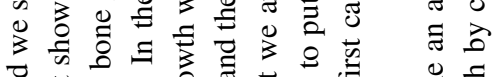

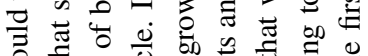
๑) 을

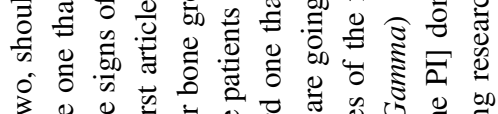

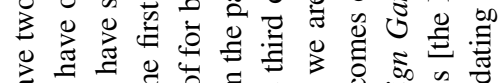

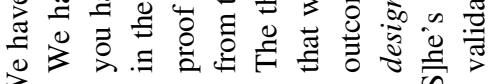

I $=\frac{\pi}{0}$

$\cong \ddot{0}$

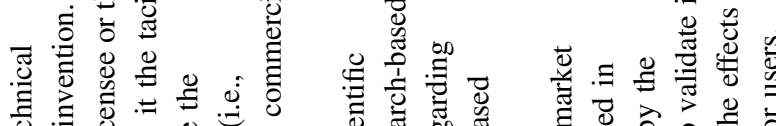

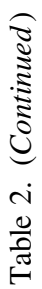

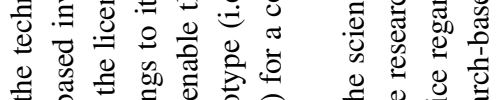

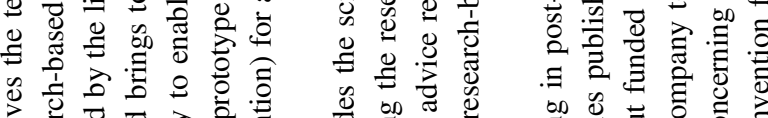

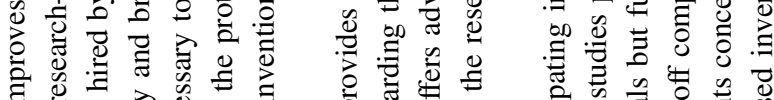

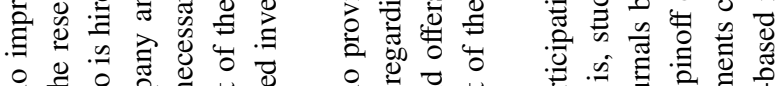

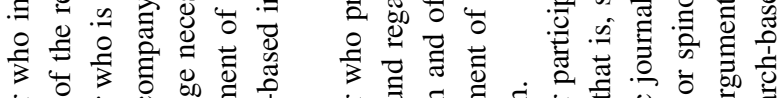

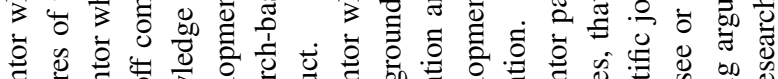




\section{A. Brantnell \& E. Baraldi}

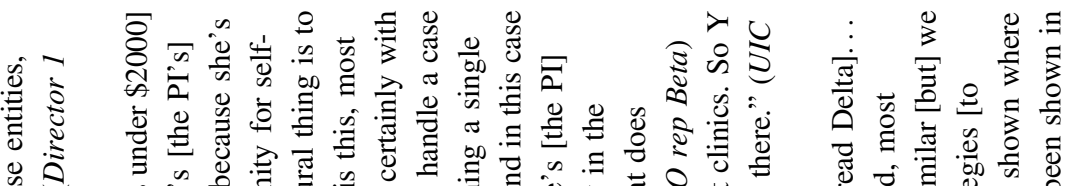

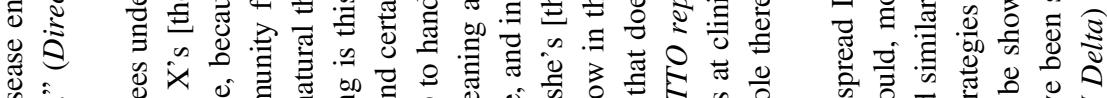

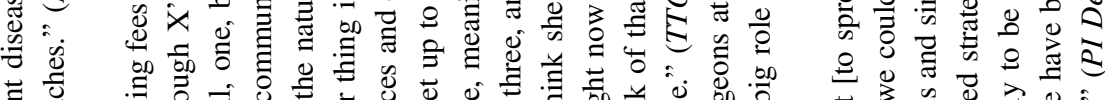

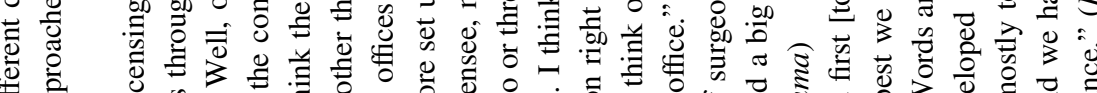

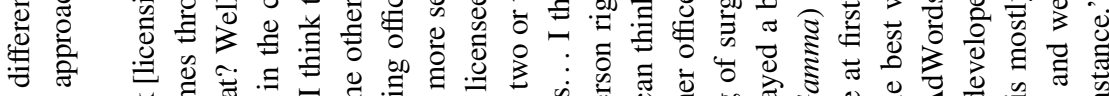

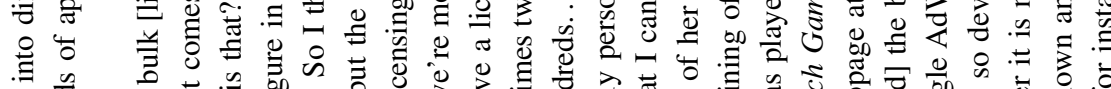

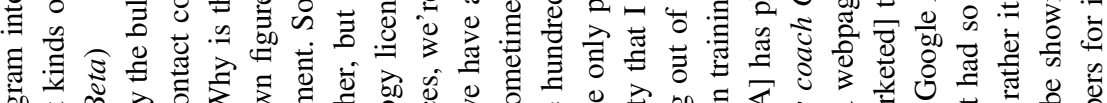

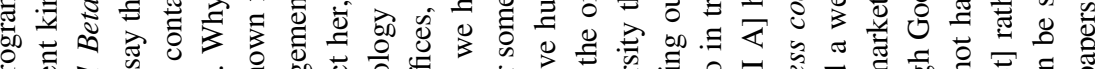

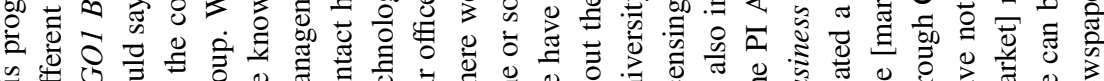

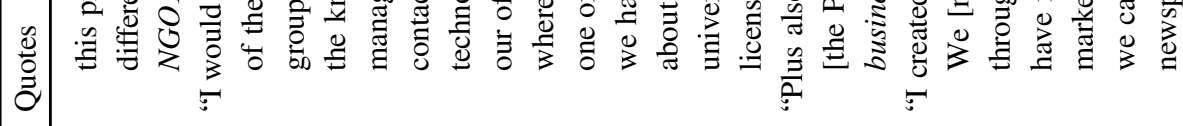

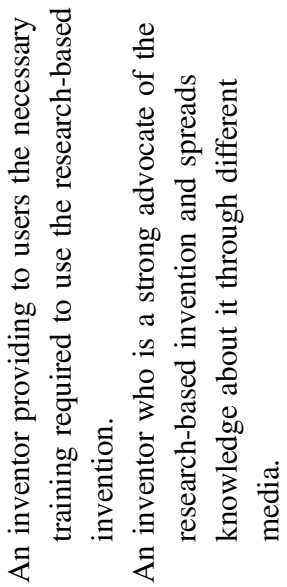




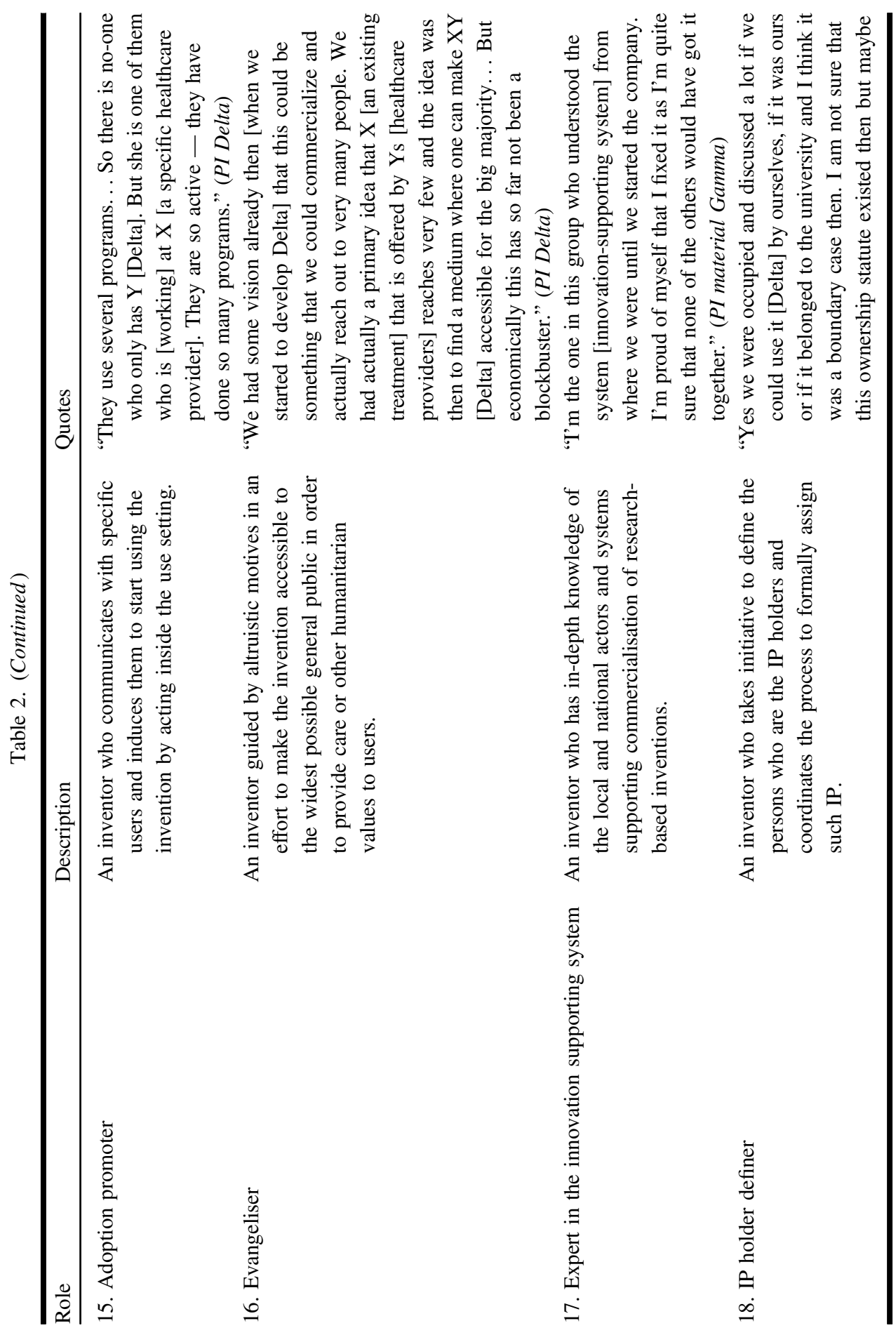




\section{A. Brantnell \& E. Baraldi}

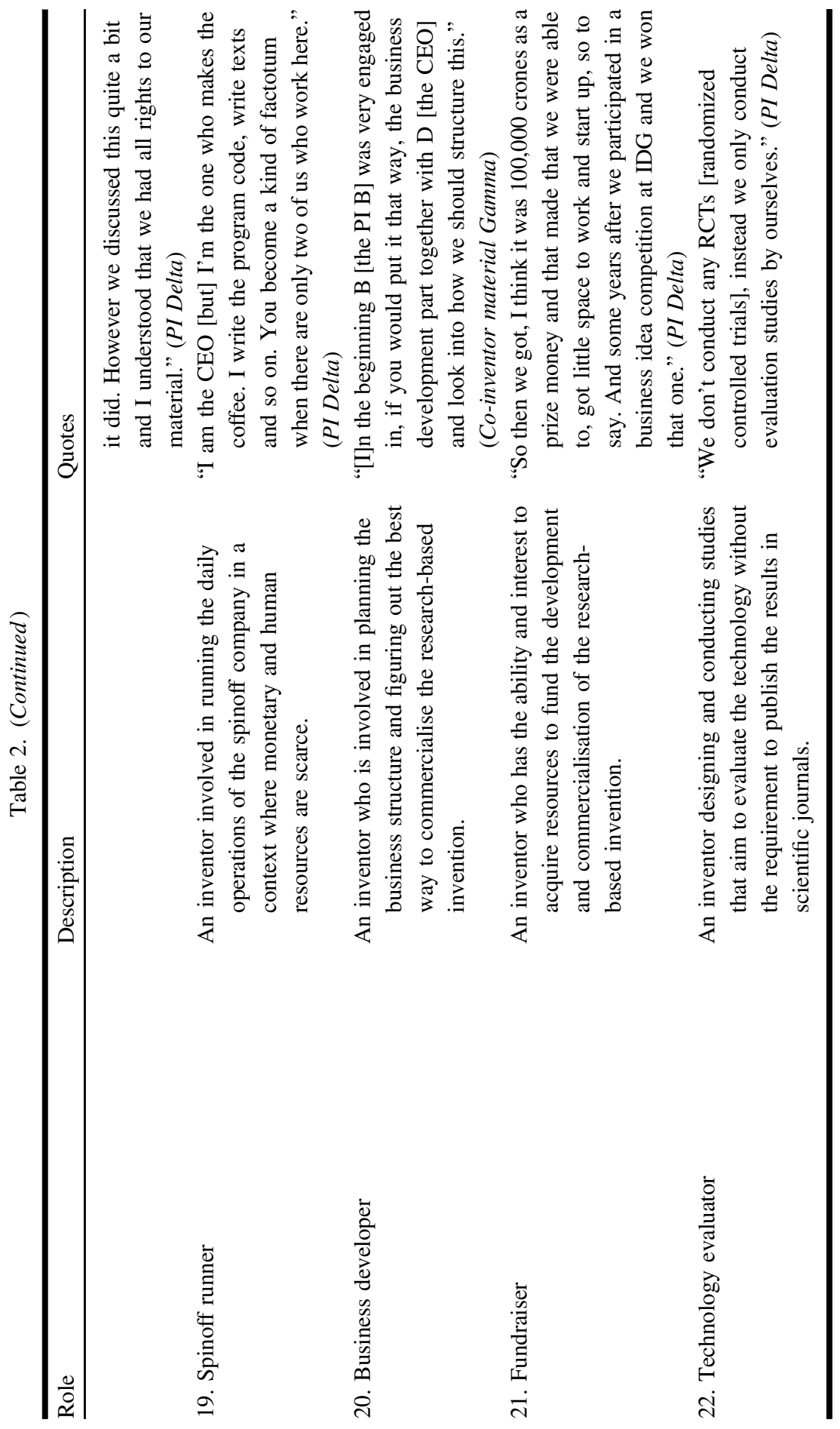


Company X conducted clinical studies with promising results, but they deemed the market for Alpha to be too small and returned the license to Stanford in 2004. Following this, the PI acted again as the broker teaming up with $\mathrm{Dr} \mathrm{C}$, who was a surgeon, and with two other partners, both experienced medical technology entrepreneurs. These four founded a spinoff company, which purchased the license for Alpha in 2005. Based on this, the PI undertook two roles that we labelled as spinoff founder and spinoff shareholder, respectively. The spinoff founder role was one task among others and took place once, which makes it a low-intensity role. The spinoff shareholder role in turn was also one task among others, but took place continuously making it a medium-intensity role.

Preceding the establishment of the company and the licensing of Alpha, the PI acted again as the technology transfer driver: together with the other spinoff founders, he hired an experienced CEO from an established medical company, who in turn recruited a highly qualified management team. No avenues were closed in the beginning, but after a detailed analysis, the spinoff company decided to focus on certain open surgery fields where the regulatory path was relatively short and the market large. The spinoff company received VC funds from two different rounds amounting to approximately \$29 million. The co-inventor was hired by the spinoff company and became a full-time engineer, taking on a role that we labelled as a technology developer:

"Well, Y [the co-inventor] actually became an employee of Alpha so he was one of our engineers so that was his role." (CEO spinoff Alpha)

Moreover, the co-inventor was also perceived as the main link that made the transformation of academic knowledge into the development of a medical product possible, a role that we labelled as a knowledge carrier:

"We hired him [the co-inventor] about a month, two months after I started. It gave us a scientific wing to the engineering group... And it helped translate and make that transition from the lab to engineering and development, and products that will actually sell and be functional for higher volume production." (Directorl spinoff Alpha)

Both roles, the technology developer and the knowledge carrier, were equivalent to full-time employment and took place continuously, making them high-intensity roles. After the establishment of the company and the hiring of the co-inventor, the PI was employed full time at Stanford, but continued to contribute to the development of technology on occasions, which we labelled as the role of technical consultant: 
"X [the PI] was really just a consultant. So X was still a Professor at Stanford. He had that position. Yes, he was a founder so he had shares in $\mathrm{Z}$ [the spinoff company] but he just came by on a consultancy basis as needed." (CEO spinoff Alpha)

The technical consultant role was performed several times but was one task among others, making it a low-intensity role. Moreover, the PI contributed not only to the development of technology but also to defining the IP held by the company: therefore he acted again as the IP co-drafter during the early spinoff years, a role that we have already defined as one of low intensities.

When the FDA approval was received in 2008, the spinoff company conducted clinical post-marketing studies to demonstrate the claimed advantages of Alpha and hired a sales force to promote the technology. No clinical trials prior to the FDA approval were required as Alpha was deemed to show substantial equivalence compared with existing technologies on the market and thus the simplified 510k procedure was exploited. The PI did not lead but still indirectly contributed to these studies, thus playing the role of technology validator:

"If I'm a Stanford employee, the technology's licensed from Stanford, belongs to Stanford, Stanford doesn't conduct, or refuses to conduct clinical trials of this technology because they consider it a conflict of interest, so all the clinical trials were conducted outside and that was a big loss for us, because then I cannot be an active participant of this... and even in one paper I was co-author, but I couldn't be very actively involved. I was consulting and helping but not as much as I would be here." (PI Alpha)

The role of technology validator was a low-intensity role as it was one task among others and took place on several occasions. Following the post-market studies, the first real users were recruited in 2008. Alpha was welcomed by younger more technology-driven surgeons, who appreciated speed and precision, whereas older surgeons expected something that they were used to and thus they were somewhat cautious. After having been one of the fastest growing new medical companies, the spinoff company was acquired by a large medical device company in 2011. During the whole innovation journey, the PI conducted research in his laboratory studying the invention further and therefore playing a role we labelled furthering research: 
"I continued studying the interactions, the mechanisms for interaction, so we can keep improving since 99 when we started here until probably 2010 or so [when the funding ended]." (PI Alpha)

This role was a high-intensity role as it took place continuously and corresponded to full-time employment.

\section{Beta from Stanford University (non-patentable IP owned by the university)}

Researcher D (the PI) at Stanford University had previously developed several self-management programs, provided through workshops by lay leaders, to support patients with various diseases. In 2003, she noticed that one specific disease that is one of the most prevalent diseases in the western world needed a new form of treatment since the existing programs were generally ineffective. The identified disease was included in the existing programs, but as this specific disease was behaviourally extremely complex, a program focusing specifically on it was needed. To this end, the PI started developing a self-management program, here labelled as Beta, in 2003. Upon completion of the development of the program, the PI acted as the discloser revealing Beta to Stanford OTL in 2008, a role that was of low intensity because it was one task among others and took place only once. Thereafter, the PI became the technology transfer driver investing a considerable amount of time to accomplish the technology transfer, equivalent to part-time employment and occurring on several occasions, entailing accordingly a mediumintensity role. In the context of use, the intended users were initially community organisations and subsequently healthcare providers. Participation was free of charge for patients and Beta - a six-week long workshop led by lay leaders was accompanied by a self-help book provided by the using organisations. Initially, Beta was welcomed by many users who appreciated the fact that it came from Stanford, but getting general practitioners to refer patients to Beta was somewhat difficult.

During the innovation journey, the PI negotiated continuously with the end users interested in using the invention and managed the whole process from first contact to the signing of the licensing contract. This set of undertakings constitutes a role that we labelled as licensing manager:

"I would say the bulk [licensing fees under \$2000] of the contacts comes through X's [the PI's] group. Why is that? Well, one, because she's the known figure in the community for selfmanagement. So I think the natural thing is to contact her, but the other thing is this, most technology licensing offices and certainly with our offices, we're more set up to handle a case where we 
have a licensee, meaning a single one or sometimes two or three, and in this case we have hundreds... I think she's [the PI] about the only person right now in the university that I can think of that does licensing out of her office." (TTO rep Beta)

The PI also upheld the structure that enabled the dissemination of the invention and was continuously involved in the practical work, providing training to end users aiming to use the invention. We labelled this role as a technology trainer:

"So X's [the PI's] focus, and the focus of most of the diffusers, is really on the training and the workforce aspects of this, and not on the kind of organizational redesign and financing that has to happen, to really embed these types of programs." (Director NGO2 Beta)

The PI has continuously been spreading knowledge about the invention and has been a strong advocate of it, thus taking on a role that we labelled a technology promoter:

"She [the PI] invented it. And she spreads it. She's a big world figure for this work. She's an incredibly strong advocate... She [the PI] goes all over and talks about it [program]." (Director1 NGO1 Beta)

All three roles, licensing manager, technology trainer and technology promoter, were high-intensity roles as they were played continuously and corresponded to full-time employment. In the context of use, the PI was also in contact with the end users in order to facilitate use, thus assuming a role that we labelled adoption promoter:

"X [the PI] would see other aspects. For example, things like adaptations and those. Then I know that she has participated, for example, on larger scale things." (TTO rep Beta)

Adoption promoter was a role that occurred several times, even though it was one task among others, thus making it a low-intensity role. During the program adoption, a large NGO X perceived that the programs were credible Stanford products coming from a leading expert in the field and started to lobby for the adoption of the programs in the US and engaged many organisations including several philanthropic organisations. When Beta was introduced in the use setting, there was no reimbursement mechanism and organisations willing to offer it needed to cover the costs in some other ways. In 2012, the campaign driven by 
NGO X eventually ended with Beta being made billable to Medicare, which allowed organisations that offered it to be reimbursed. Beta is at the moment one of the fastest growing self-help programs in the US, but it is also used outside the US in many European countries. Stanford OTL acknowledged that their office was not created to manage hundreds of small licenses and that a successful technology transfer would not have taken place without the continuous and in-depth involvement of the PI. The inventor was guided by almost altruistic motives in her efforts to make the invention available, something that we labelled as the role of an evangeliser:

"I think her [the PI's] desire was always that the work gets used and that it becomes accessible. So she, in terms of her role on the licensing side, has always really been driven from that desire to make it accessible. So she has then made resources available within her own office to facilitate a little out of the licensing." (TTO rep Beta)

The role of evangeliser was a high-intensity role as it was played continuously and corresponded to full-time employment. Like in the Alpha case, also Beta's PI has been and still is furthering research. This role was a high-intensity role as it took place continuously and corresponded to full-time employment.

\section{Gamma from Uppsala University (patentable IP owned by the inventor)}

Dr. E, a Swedish plastic surgeon and a researcher (PI design), noticed in 2005 that patients suffering from head trauma had complications with the existing treatments. Faced with this, PI design developed an alternative concept addressing the shortcomings of the existing treatments. In 2008, PI design met Engineer C (co-inventor design), who started to materialise PI design's idea and came up with a solution in 2009. However, PI design and his co-inventor lacked a suitable material to produce it. At the same time, Uppsala University Professor F (PI material) had together with his PhD student (co-inventor material) developed a certain material compound that could be used to fix small bone defects. Gamma was born when PI design became aware of PI material, and the latter understood that his material could be used in the solution devised by PI design and his co-inventor. To this end, a prototype was created in 2010. PI material had already contacted the local TTO, Uppsala University Innovation (UUI) and the holding company Uppsala University Development Ltd. (UUAB) in 2008 regarding this previously developed material. Therefore, PI material acted as the technology transfer driver. Moreover, he had already in-depth knowledge of the actors and processes supporting the commercialisation of academic inventions at Uppsala 
University, and therefore he was capable of taking on a role that we labelled as expert in the innovation-supporting system:

"I'm the one in this group who understood the system [innovationsupporting system] from where we were until we started the company. I'm proud of myself that I fixed it as I'm quite sure that none of the others would have got it together." (PI material Gamma)

Both roles, technology transfer driver and the expert in the innovation-supporting system, were played several times but they were tasks among others and accordingly represent low-intensity roles. PI material was also the broker and involved a business person, CEO C and together with him applied for verification funding from Sweden's Innovation Agency (Vinnova) in 2009, receiving approximately $\$ 200,000$ for development. Also this role took place several times but was one task among others, thus resulting in a low-intensity role. Also with Gamma, which combined the original material into a solution for head trauma patients, PI material was the technology transfer driver, the expert in the innovationsupporting system and the broker connecting UUI and the four inventors. To test the feasibility of Gamma, PI design operated on two incurable patients and in this way connected the inventors with one major Swedish Hospital - Hospital X — acting as the broker.

In 2011, together with CEO C and four other researchers from the material compound project, the four inventors founded a company and accordingly played the role of spinoff founders: this role occurred only once and was one task among others leading to a low-intensity role. Moreover, the four inventors together became spinoff shareholders in the newly founded company: even if this was one task among others, they retained their shares for a long time and played this role continuously, making it a medium-intensity role. Preceding the establishment of the spinoff, PI design took the initiative to define who among the various people involved should be the IP holders, a role that we labelled as an IP holder definer:

"I'm probably the one who was driving it [to define who should be in the patent] forward and initiated the process. Then $\mathrm{X}$ and $\mathrm{C}$ [co-inventor design and co-inventor material] were part of it and A [PI design] has been part of the process." (PI material Gamma)

This role constituted in this case a low-intensity role as it was played once and was one task among others. CEO $\mathrm{C}$ became the CEO of the spinoff company and co-inventor material ended up running it, thus assuming the role of a spinoff runner:

"You do everything on the scale [activities required in a spinoff]."

(Co-inventor material Gamma) 
Co-inventor material was one of the only two full-time employees at the spinoff, making the spinoff runner role a high-intensity role as it occurred continuously and corresponded to full-time employment. The spinoff company went through two rounds of VC funding and received altogether about $\$ 2.3$ million. Following the founding of the spinoff, co-inventor material started to develop Gamma towards a sellable product with the help of co-inventor design, and both acted as technology developers, which was a high-intensity role because it was played continuously and corresponded to full-time employment. A significant milestone was achieved at the end of 2014 when the spinoff company felt that Gamma was scalable. PI design, who was also a clinical professional treating patients, became employed by the spinoff in order to reach out to people and spread knowledge of Gamma as a solution to attract interest and eventually customers, becoming the technology promoter:

"I'm the one who has contact with other clinicians and tries to get people to notice this [Gamma]." (PI design Gamma)

PI design also acted as the technology trainer while still continuing working as a part-time clinician. Consequently, the two roles, technology promoter and technology trainer, were medium-intensity roles because they were played continuously and corresponded to part-time employment. The spinoff company notified the Swedish Medical Products Agency, but no clinical trials prior to marketing were required as Gamma was deemed to resemble other existing products on the market concerning materials and function. Following this procedure, Gamma was CE marked. PI material was involved in planning the structure for the business and figuring out how to commercialise Gamma, a role that we labelled a business developer:

"In the beginning, B [PI material] was very engaged in, if you would put it that way, the business development part together with $\mathrm{C}$ [the $\mathrm{CEO}$ ] and looked into how we should structure this." (Co- inventor material Gamma)

PI material also had the ability and interest to acquire funding, an activity that we labelled as the role of fundraiser:

"B [PI material] has always been good at getting in soft money continuously." (Co-inventor material Gamma)

PI material also acted as the IP co-drafter. All three roles, business developer, fundraiser and IP co-drafter, were low-intensity roles as they occurred several times but were tasks among others. While decreasing his direct involvement in the spinoff, PI material continued conducting research on Gamma at the university, 
thereby playing the role of furthering research continuously and as a full-time job, making this a high-intensity role. Moreover, PI material has played the role of technical consultant for the company several times, but since this role was one task among others, it remained a low-intensity role. PI material was able to play this more distant role because his former $\mathrm{PhD}$ student, co-inventor material, acted on a continuous basis as the knowledge carrier corresponding to full-time employment, making this a high-intensity role. When the spinoff company conducted postmarket studies to support the claimed advantages of the technology, both PIs, design and material, acted as technology validators on several occasions, but since this role was one task among others its intensity was low. When Gamma was introduced to surgeons, the intended users, some were interested in trying it out, whereas others were cautious as they were satisfied with the existing treatments. The spinoff is growing and expansion is planned.

\section{Delta from Uppsala University (non-patentable IP owned by the inventor)}

The idea to offer self-help programs via the Internet to patients afflicted with various mental health problems was born when two psychology students at Uppsala University decided to try this with certain patients at the end of the 1990s. The study had promising results, inducing one of them to become a PhD student. The first study developed by the PhD student as the PI and the other student as the co-inventor targeted another patient group, and also with this patient group the Internet format was perceived as promising by the PI. Consequently, an innovation, labelled here as Delta, was born. The PI took on the role of the technology transfer driver, a role that he played continuously throughout the innovation journey and that corresponded to full-time employment, making this a highintensity role. The PI maintained his position as a $\mathrm{PhD}$ student and was simultaneously involved in the commercialisation of Delta. As part of the technology transfer driver role, the PI consulted UUAB in 1999 to discuss a technology transfer. However, the PI appeared uninterested and the cooperation with UUAB ended before it had even got started. The PI also acted as the IP holder definer, undertaking this role once and as one task among others, which makes it a low-intensity role. Moreover, he played the role of technology promoter, which included, for instance, the creation of a webpage for dissemination in 1999. The technology promoter role was a high-intensity role as it was undertaken continuously and corresponded to full-time employment.

While continuing acting as the technology transfer driver, the PI also played the role of fundraiser when he participated in several entrepreneurial competitions, which awarded him soft funding for about $\$ 30,000$. At another business competition, a large financial Company F noticed the two inventors and decided to invest 
about $\$ 800,000$ in Gamma. The role of fundraiser was played several times but was only one task among others, thus constituting a low-intensity role. In 2001, the inventors became spinoff founders when they started Spinoff A together with a business developer (CEO Spinoff A) and a couple of other researchers from Uppsala University, who together became spinoff shareholders. The spinoff founder role was undertaken by the PI several times (a second spin-off was founded later), but was one task among others thus constituting a low-intensity role; whereas the spinoff shareholder role was one task among others but was played continuously, constituting therefore a medium-intensity role. The CEO of Spinoff A, the PI and the co-inventor became employees of Spinoff A. The other Uppsala researchers held other positions, and some of them left the company quite soon after its establishment as they preferred to continue with their academic careers.

Spinoff A started growing and managed to get some users to try out Delta, but in 2003, after the financial Company F experienced a major financial crisis, it withdrew funds from all its non-public investments, causing Spinoff A to declare bankruptcy. The CEO of Spinoff A bought the bankruptcy estate at this point and founded Company C. The PI started a new spinoff company (Spinoff B) in parallel, thus again becoming a spinoff founder, to commercialise the principles that Delta was built on. Accordingly, he continued acting as the technology transfer driver and as the technology promoter. Also the co-inventor participated in spinoff $\mathrm{B}$ and became a spinoff shareholder. The PI and the co-inventor had to write new programs because the copyright for Delta was owned by the bankruptcy estate and thus became available only to Company $\mathrm{C}$.

In terms of customer segmentation, Company $\mathrm{C}$ focused on private customers and company healthcare, whereas Spinoff B focused on private customers and healthcare providers. Soon after its establishment, Spinoff B chose to launch Delta as its flagship program. The costs of enrolling in Delta - an eight week's Internetbased self-help program - are covered by the individuals and there is also a selfhelp book available that can be purchased to accompany the program. Spinoff B has also licensed Delta to major organisations such as a Swedish pharmacy chain, one Swedish tabloid and one Spanish company, who all made Delta available to their individual customers. Spinoff B has been run mainly by the two academic inventors, with the PI investing a considerable amount of time, corresponding to full-time employment, to accomplish the technology transfer and becoming a spinoff runner:

"I'm the CEO [but] I'm the one who makes the coffee. I write the program code, write texts and so on. You become a kind of factotum when there are only two of us who work here." (PI Delta) 
The spinoff runner role was undertaken continuously and corresponded to fulltime employment, making it a high-intensity role. The PI also took care of the design of the solution and conducted studies aiming to evaluate the technology, albeit without scientific aims: this is a role that was not present in the other three cases and that we labelled the technology evaluator:

"We don't conduct any RCTs [randomized controlled studies], instead we only conduct evaluation studies by ourselves." (PI Delta)

In addition, the PI also acted as the adoption promoter and the licensing manager. All three roles, technology evaluator, adoption promoter and licensing manager, were undertaken several times, but since they were still tasks among others, they all three represent low-intensity roles. The PI invested a considerable amount of time and personal effort, although Delta did not become a blockbuster and did not provide much in terms of economic returns: therefore, the PI has acted as the evangeliser, which was a high-intensity role, occurring continuously and corresponding to full-time employment. The co-inventor in turn acted as the technology developer in order to improve the technology and invested continuously a considerable amount of time, corresponding to full-time employment, making this a high-intensity role:

"[I've been working as a] Web developer and program developer... for approximately 10 years now... Since the establishment of the companies [Spinoff A and Spinoff B] we have only periodically been able to live on income from the companies." (Co-inventor Delta)

In trying to commercialise the self-help programs, Spinoff B has chosen not to take in VC funding because of the negative experience with Company F. Both Spinoff $\mathrm{B}$ and Company $\mathrm{C}$ have helped thousands of patients and contributed to the growing interest in Internet-based self-help programs. Spinoff B acknowledged that it is difficult and time-consuming to sell Delta to the public healthcare providers. Despite the growing interest, both companies still consider that Internetbased self-help programs are not sufficiently established among users and the general public and that the commercialisation efforts were 10 years ahead of time.

\section{Discussion}

This section analyses the four cases aiming to identify how IPR ownership and IP nature influence the academic inventors' roles and role intensities. 


\section{Different occurrences of roles and different levels of role intensity in the four cases}

We analyse the various roles and their intensities in order to propose tentative explanations for the differences regarding occurrence and intensity in the four cases, thereby addressing the purpose of this paper: examine the roles of academic inventors during the entire innovation process and identify how IPR ownership and IP nature might influence these roles. We discuss all roles that seem to be influenced by IPR ownership and IP nature. In addition to IPR ownership and IP nature, we identify and consider other possible factors that could influence the specific inventor roles and role intensities and discuss such roles and factors.

\section{The IPR ownership system and inventor roles}

Altogether, two roles appeared only in the cases with the same IPR ownership: discloser and IP holder definer. As it might be assumed, the role of discloser (Siegel et al., 2004) was only present in the two cases concerning inventions that are owned by the university. Moreover, interestingly, in both these cases, the intensity of the discloser role was low, which indicates that disclosing your research results to the TTO is not a demanding task in terms of required time or involvement, even though this role might need to be stimulated as inventors may not be prone to disclose for other reasons than lack of time (Siegel et al., 2003; Owen-Smith and Powell, 2001). Discloser was a competence-based role in which the regulatory framework might require disclosing, as was the case at Stanford, and the inventor had the competence to undertake the role, which allowed the innovation process to proceed.

The role of IP holder definer was manifested only in the cases with inventor ownership. IP holder definer is a role that is necessary in an inventor ownership system like in Sweden (Farnstrand Damsgaard and Thursby, 2013) because defining who contributed to the invention determines who will become the IP holders entitled to exploit the IP. In contrast, in a university ownership situation, the role of IP holder definer is absent because the university automatically becomes the IP holder after the disclosure (Kenney and Patton, 2009). IP holder definer was a low-intensity role, which is reasonable because, excluding cases of disputes on discoveries or highly complex inventor teams, identifying the researchers who contributed to the invention is probably not a demanding task. IP holder definer was a role that the inventors undertook because they held a certain position awarded by the regulatory framework around the IP.

\section{The type of invention (patentable versus non-patentable IP) and inventor roles}

Altogether 10 roles appeared only in the cases with the same IP nature: IP co-drafter, technology transfer driver, broker, knowledge carrier, evangeliser, 
technical consultant, technology validator, licensing manager, adoption promoter and technology promoter. These 10 roles will be discussed below.

The IP co-drafter role was played by inventors only in the two cases with patentable IP, which is logical as those types of inventions can and indeed need to be protected through carefully drafted patents, which is not the case for nonpatentable IP. In particular, the role of IP co-drafter seems to be a low-intensity role, which is reasonable as the academic inventor contributes his knowledge to the patent application, a knowledge that largely builds on the academic inventor's research and which is easily available to the inventor. IP co-drafter was a role that the inventor undertook because he held a certain position in relation to the invention based on the regulatory framework around the IP, especially the patentability of the invention.

The role of technology transfer driver was manifested in all four cases. However, the intensity of this role differed: the patentable inventions displayed a low intensity, whereas the non-patentable inventions displayed either medium intensity (Beta) or high intensity (Delta). Our interpretation is that the two patentable inventions (Alpha and Gamma) were easy to define and codify and thus, pushing for utilisation outside academia was comparatively less demanding than for Beta and Delta, which were more unusual products that could not be easily defined and required a more demanding and time-consuming role of technology transfer driver. What causes the difference in intensity between Beta and Delta? Here, one can consider the fact that Beta from Stanford was bound to receive support from the TTO, which eased the burden of being the "driver" for the inventor to a medium level; whereas the inventors behind Delta from Uppsala chose to pursue utilisation alone (without relying on the local TTO) and thus had to take on the technology transfer driver role themselves more fully and with greater intensity. Technology transfer driver was an activity-based role adopted voluntarily by the inventors of Alpha and Gamma who speeded up the technology transfer, whereas it was a matter of necessity for the non-patentable inventions Beta and Delta, which would not have been commercialised at all without the inventors acting as technology transfer drivers.

The role of broker was present only in the two patentable IP innovation journeys and was a low-intensity role. Brokering was an activity-based role taken on voluntarily by the inventors to better support the inventions Alpha and Gamma. This role entails finding people and organisations which are relevant for continuing the commercialisation process and connecting the inventors or the spinoff company with them (Cunningham et al., 2015; Mangematin et al., 2014). This kind of role is likely to occur and is more relevant if the IP is clearly described and codified in patents (Arrow, 1962), that is, if the knowledge is explicit, and thus the inventor can assume the role of finding people and organisations interested in 
exploiting the explicit knowledge about his invention. Furthermore, the inventors undertaking the role of broker in the two cases (Alpha and Gamma) had already established contacts with the industry and the TTO, which rendered this role less demanding and hence was of a low intensity. Playing such a role with nonpatentable inventions, with IP that is much more difficult to explain and defend, would instead be a more unlikely and certainly a more difficult and demanding role. We cannot indeed see any traces of the broker role in the non-patentable inventions, where instead inventors were themselves active in roles with direct (i.e., not brokered) connections with users, namely, adoption promoter, licensing manager and evangeliser, as will be shown below.

The role of knowledge carrier was only present in cases with patentable IP and was a competence-based role induced by external circumstances, that is, in order to develop the invention into a product, the spinoff needed a very specific competence which the co-inventors held. Transferring knowledge from academic research to industrial production is a heavy and demanding task due to the considerable differences between these settings (Håkansson and Waluszewski, 2007). Therefore, it is not surprising that this role is a high-intensity role in the two cases in which it appeared. In patentable IP, the role of knowledge carrier reflects the need to add personal knowledge to the IP due to its technological weight and complexity (Feller and Feldman, 2010). The spinoff company needs the expertise of the inventor and thus hiring the academic inventor or co-inventor facilitates the exploitation of the IP: as one of the spinoff company representatives expressed it, hiring the co-inventor gave a "scientific wing" to the engineering team. In contrast, the role of knowledge carrier, which in our study corresponds to being hired by the spinoff for the sole purpose of transferring knowhow to it, does not appear in inventions with non-patentable IP. Knowhow was of course also needed to exploit the non-patentable IP, but in those cases the knowhow was so embodied in the original inventors, the very PIs, that in order to become available to final users it required a broader and more personal type of involvement, namely, undertaking the role of evangeliser.

The role of evangeliser was a high-intensity role and was required probably because the IP had not been clearly codified and thus could not be transferred through a co-inventor (who could have acted as a knowledge carrier). Another reason for the emergence of this role was that both Beta and Delta entailed IP that was not commercially viable per se and, since no licensing company was interested in taking the lead in its exploitation, the inventors had to make substantial personal investments to turn their inventions into solutions available to patients. Evangeliser was an activity-based role, which the inventor voluntarily chose to perform in order to support the innovation process. 
Technical consultant was a low-intensity role played by the main inventors (the PIs), and appeared only in the two patentable inventions, where the co-inventors took the high-intensity roles of technology developers and knowledge carriers to transfer knowhow from academia to industry, and thereby allowed the main inventors (the PIs) to take on the more distant role as technical consultants. Technical consultant was a competence-based role carried out by the inventor because of the external circumstances, that is, the spinoff needed advice regarding the technology and the inventor could contribute with the relevant competence. This role is widely recognised in previous research (Boehm and Hogan, 2014; Braunerhjelm and Svensson, 2010; Jensen and Thursby, 2001; Siegel et al., 2004; Thorburn, 2000; Zucker et al., 2002), although its intensity has not been addressed. One might expect the role of technical consultant to be highly intensive because developing a prototype into a product can indeed be a demanding task. However, our cases indicate that the involvement of co-inventors as knowledge carriers and technology developers may entail a lower intensity of the role of technical consultant played by the main inventor.

Also the technology validator role appeared only in the two patentable inventions: a possible explanation is that this role entails participating in postmarket studies, which do not seem to be important for non-patentable low-tech innovations such as Beta's self-management program or Delta's online-based selfmanagement program that built directly on the results of the clinical studies from academia. The role of technology validator was a low-intensity role, which could be explained by the fact that the undertakings it embodies (evaluations, comparisons and measuring of effects) are close to the daily work of the academic inventor as a researcher and required relatively few new efforts. Technology validator was a competence-based role performed largely due to external circumstances, that is, the spinoff needed to conduct post-market studies and the competence of the inventor in these areas was crucial.

The role of licensing manager was only present in the non-patentable inventions, but the intensity of the role varied, and was high in Beta but low in Delta. A licensing manager is an unusual role in which the inventor takes on a role that actually belongs to the TTO in systems where the IP is owned by a university. However, as Beta was a rather peculiar invention for Stanford and attracted several small licensees, the TTO was not able to handle these kinds of small licenses issued to many parties. Facing this problem, the inventor undertook a demanding high-intensity role where she partly replaced the TTO. In contrast, Delta was a treatment distributed through the Internet mostly to individuals or via a few major healthcare providers and thus no high-intensity licensing manager role was required. A licensing manager was a position-based role, which the inventors were more or less forced to play because no one else was in the position to play it and 
licensing was the necessary channel for spreading the two non-patentable inventions to users.

The role of adoption promoter was played only in the non-patentable IP cases and was a low-intensity role. Like the role of technology promoter, this role may reflect the tacit nature of non-patentable IP too, requiring the involvement of inventors in use settings, where they facilitate the use of an innovation with high levels of tacit knowledge. In contrast, the more codified nature of patentable IP did not require that inventors promoted adoption in use settings because the knowledge was codified in manuals and patents or embodied in the physical products (Alpha's surgical device and Gamma's implant). The adoption promoter role could be a rather demanding role because facilitating clinical use requires time and a good understanding of the clinical context (Rycroft-Malone, 2004). However, in our two non-patentable IP cases, the inventors could not be high-intensity adoption promoters because they had to play more or less simultaneously many other roles for Beta and Delta, respectively. Adoption promoter was an activity-based role, which the inventors chose freely to perform to support the needs of the specific innovation process.

The last role whose occurrence and intensity seem connected to the IP nature is that of technology promoter, which appeared in three cases (Beta, Gamma and Delta) and was a high-intensity role in the two non-patentable inventions (Beta and Delta) and a medium-intensity role in the patentable invention (Gamma). The fact that the intensity of this role differed between non-patentable and patentable inventions may depend on the fact that the former entailed higher levels of tacit knowledge (von Krogh et al., 2000) and hence required academic inventors to spend more time and energy in promoting the complex and fuzzy knowledge behind their invention to different audiences, whereas codified knowledge is less demanding to promote. As for Alpha, the inventor did not need to undertake this role because the promotion of the technology was taken care of by the company's professional sales force. Therefore, the emergence and intensity of the technology promoter role seems to be connected both to the nature of the IP of the invention and to the possibility that these activities are taken over by a dedicated organisation such as a spinoff company. Reflecting these aspects, technology promoter is a role which can be seen both as competence-based, insofar as it relies on the inventor's competence which is necessary to promote non-patentable, less codified inventions and as an activity which needs to be performed by the inventors if the commercialising entity lacks the resources to take care of technology promotion.

\section{Other factors and inventor roles}

There were altogether 10 roles which appeared in the four cases but could not be connected uniquely to a particular IPR ownership structure or IP nature: spinoff 
runner, fundraiser, spinoff founder, spinoff shareholder, technology developer, furthering research, technology trainer, expert in the innovation supporting system, business developer and technology evaluator. Below we will discuss the roles where we can single out one specific factor, other than IPR ownership and IP nature that seems driving them. Spinoff runner was a high-intensity role in the Gamma and Delta cases from inventor ownership systems, whereas it was altogether absent in the Alpha and Beta cases from university-ownership systems. While this role was excluded in the Beta case, because no company was started to distribute the invention, it could still have appeared in Alpha. One possible explanation for these differences in the occurrence of the spinoff runner role can be found in other contextual conditions than IPR ownership or IP nature. In particular, Alpha was invented in Silicon Valley, which provides ample possibilities to find a qualified workforce and attract venture capital and even entrepreneurial teams. In contrast, Gamma and Delta were invented in Uppsala, where a qualified workforce and venture capital are more difficult to come by. Consequently, the academic inventors behind Alpha did not need to undertake the spinoff runner role as the company could attract enough funding to be able to hire a management team to run the spinoff. In contrast, Gamma and Delta were commercialised by companies that were run mainly by the inventors and the co-inventors, who accordingly had to become spinoff runners. Thus, spinoff runner was an activity-based role, which the inventors were basically required to perform in the cases of Gamma and Delta due to local context-specific difficulties in hiring personnel for those spinoffs.

Following the same logic of contextual conditions, the fundraiser role was only manifested in the cases with inventor ownership, but more importantly, in our study they correspond with the local context, Uppsala, with limited venture capital. Despite potential difficulties in finding funds in this context, the fundraiser role was a low-intensity role because it was just one of the many tasks that the inventors undertook. The role of fundraiser entailed activities, which were strictly required to secure the funding in a local context with limited venture capital.

Technology developer was present in three cases (Alpha, Gamma and Delta). One explanation is that all three cases feature an invention that required further technical development. Even if these three cases differ in terms of technical features, with Alpha and Gamma emerging from academia as high-tech prototypes and Delta as a very new concept in mental healthcare delivery, they all shared the need for further development to become commercially viable. In contrast, Beta was an intervention that was eventually delivered to patients in the same form as it was conceived and tested in academic studies and therefore needed no further development. The role of technology developer seems to be connected to an important characteristic of the academic invention, namely, its degree of readiness 
for market launch, and was a high-intensity role requiring massive efforts from the inventors, because developing a prototype or an early concept into a scalable commercial product is complicated, risky and time-consuming. Thus, the role of technology developer was based on the competence of the inventor, which was necessary for the further development of the invention.

Technology trainer was a role present in two cases, Beta and Gamma, but with different intensity. For Beta, this role was present with high intensity, as the inventor participated in the dissemination of the invention on a day-to-day basis by training a large number of new users; whereas for Gamma it was present with low intensity, as one of the PIs trained a few new surgeons but this was not his fulltime job. The role of technology trainer was competence-based emerging from the necessity to train new users and the availability of the inventor's competence to do this. Interestingly, also Alpha required the training of new users, but the company commercialising Alpha had a sales force to sell and promote Alpha and thus the inventor was not required to undertake that role. Finally, the role was not relevant for Delta as the Internet solution did not require any explicit training of new users. Hence, the technology trainer role seems to be connected, not so much to IPR ownership or IP nature, but to the number and types of users who need training, as well as where the competence for such training is available, namely, a new dedicated organisation or the academic inventor.

The role of expert in the innovation-supporting system appeared in only one invention (Gamma): this particular role might become relevant in IPR ownership systems where inventors own the research results and where the inventor is required to "navigate" an intricate innovation-supporting system to identify the right external actors and resources. However, this was a low-intensity role in the Gamma case, because it did not require much time and was played only on some occasions, and was absent altogether in Delta (the other inventor ownership case), because the inventors decided to go it alone without the support of the TTO. Instead, this role loses relevance in university-ownership systems because the disclosing process moves the responsibility for the exploitation of the IP from the inventor to the university. Thus, even if relevant especially for inventor-ownership systems, the willingness of an academic inventor to rely on the innovationsupporting system seems to be a main factor behind the emergence of this expert role, which is also based on this particular kind of competence.

The business developer role was undertaken only in the Gamma case and was a low-intensity role because planning how to commercialise the invention was an important task but still only one among many others. This was a role undertaken by the inventor based on his specific competences not only on technical, but also on business and market issues. The reasons why the business developer role did not appear in the other cases differ: in the Alpha case, it was undertaken by the 
company's management team; in the Beta case, no company was created and the dissemination strategies were crafted by the TTO and finally in the Delta case, the inventors did not express any explicit role regarding business development, although it was probably a part of the CEO function that the inventor held in the second (but not in the first) spinoff company. Hence, possible factors behind the emergence of this role seem to be the goals, division of labor and resources of the organisations, which commercialise the inventions.

Table 3 summarises our analysis of the different occurrences and intensities of inventor roles displaying the possible influence of different factors. Our study is clearly exploratory and does not demonstrate any correlations or associations between the roles and various factors. It merely identifies how IPR ownership and IP nature could influence the behaviour of academic inventors and proposes explanations to why this could be the case.

Table 3. The unique occurrence and intensity of academic inventor roles in relation to identified factors.

\begin{tabular}{cccccc}
\hline University & Inventor & Patentable & Non-patentable & Other \\
ownership & ownership & IP & IP & factors \\
\hline
\end{tabular}

1. Discloser

2. IP holder definer

3. IP co-drafter

4. Technology transfer driver

5. Broker

6. Knowledge carrier

7. Evangeliser

8. Technical consultant

9. Technology validator

10. Licensing manager

11. Adoption promoter

12. Technology promoter

13. Spinoff runner

14. Fundraiser

15. Spinoff founder

16. Spinoff shareholder

17. Technology developer

18. Furthering research

19. Technology trainer

20. Expert in the innovation supporting system

21. Business developer

22. Technology evaluator
L (low)

$\mathrm{L}$

$\begin{array}{cc}\text { L } & \\ \text { L } & \text { M (medium), H } \\ \text { L } & \\ \text { H (high) } & \\ & \text { H } \\ \text { L } & \\ \text { L } & \\ & \text { L, H } \\ \text { M } & \text { L } \\ & \text { H }\end{array}$

$\mathrm{H}$

L

$\mathrm{L}$

M

$\mathrm{H}$

$\mathrm{H}$

L, H

L

L

L 


\section{The impact of IPR ownership and IP nature on academic inventors' roles}

Our findings indicate that both IPR ownership and IP nature can influence inventor roles. Related to previous research on IPR ownership, our findings do not support the notion that inventors would not have incentives to be involved in commercialisation and innovation processes when the IPR is owned by inventors (Goldfarb and Henrekson, 2003), because there is at least one inventor role uniquely connected to inventor ownership (IP holder definer, see Table 3). Our findings also indicate that IPR ownership is a factor uniquely connected to two academic inventor roles (discloser and IP holder definer) and IP nature is connected to as many as 10 roles (Table 3). Therefore, the current research and policy focus on IPR ownership should be complemented with IP nature, which according to our findings is a more prevalent and stronger factor than IPR ownership in influencing the roles and role intensities of academic inventors. Consequently, the debate concerning the primacy of certain IPR regimes (Goldfarb and Henrekson, 2003; Farnstrand Damsgaard and Thursby, 2013; Litan et al., 2008; Mowery et al., 2001; Kenney and Patton, 2011, 2012) in influencing inventors behaviour should be broadened to deal with how IP nature also shapes important roles of inventors, as well as their involvement in innovation processes.

In line with assumptions concerning patentability (Anton and Yao, 1994; Arrow, 1962) and existing findings on the importance of patents in the field of medical research (Colyvas et al., 2002; Garber et al., 2006; Pressman et al., 2006; Smith Hughes, 2001), we observe the importance of patents in providing incentives to academic inventors. However, little is known about the incentives that non-patentable medical inventions can provide to academic inventors. Our findings clearly show that non-patentable inventions too can create incentives for inventors and even entail in general higher role intensities compared with patentable IP (Table 3). Consequently, our findings do not support the sectorial or contextual argument (Artz et al., 2010; Willoughby, 2013) at least not in medical field, where both patentable and non-patentable inventions seem to create incentives for inventors, although future profits are clearer in patentable IP and create monopoly power (Clancy and Moschini, 2013). This is an important contribution towards improving our understanding of innovation processes aiming to exploit non-patentable IP in such important fields as medicine.

\section{Conclusions and Implications for Policy and Practice}

By analysing entire innovation journeys, this study identified several academic inventors' roles and their intensities, as well as how two important institutional 
factors, IPR ownership and IP nature, influence roles and role intensities. We found that different roles tend to have different intensities, but that certain roles tend to have the same intensity in all the journeys where they occur. This also implies that an academic inventor within one and the same innovation journey plays roles with a different intensity, or put differently, an academic inventor does not perform all the roles with equal intensity. Finally, all innovation journeys are clearly unique and include different roles, whose occurrence and intensity vary and can be connected to the following factors: IPR ownership, IP nature (patentable or not) and other factors such as the availability of key resources such as venture capital and qualified personnel.

Although we identify connections between factors, the roles of inventors and role intensities, our findings are only tentative because they rely only on four innovation processes from two contexts, selected from universities considered as national champions, which might introduce a selection bias giving an overoptimistic picture (Denrell, 2005). Moreover, in order to make the four innovations comparable, they were all selected from one single field, medical research. Therefore, in order to validate our findings, they should be tested on a larger sample of innovations, selected ideally from several technical and academic contexts. Furthermore, we identify inventor roles and their intensities but, within the limited scope of this paper, we do not conduct a deeper analysis of the detailed content of each role and of how the various roles are connected to each other or how the roles change over time. Such an analysis could contribute to furthering our understanding of the function and contribution of academic inventors in innovation processes and present aspects that could be addressed in future research.

Despite the limitations of this study, the following policy and managerial implications are relevant for policymakers at three levels: lawmakers, research funders and university administrators. First, lawmakers should be aware that the IPR ownership regime, which they may legislate, is only one among the many other factors that may influence the roles undertaken by academic inventors. While since the Bayh-Dole Act of 1980 there has been much focus in policymaking on the IPR ownership (Farnstrand Damsgaard and Thursby, 2013), lawmakers and policymakers should also consider that certain types of inventions, namely, non-patentable ones, may entail inventor roles such as that of evangeliser and licensing manager, which need particular policy consideration or support. Secondly, research funders who design policies concerning funding and implementation should consider that academic inventors can enact roles during the entire innovation process and thus specific resources for exploitation and commercialisation would be needed for such purposes. However, exploiting and commercialising non-patentable IP is in general more complicated and demanding and entails different roles and higher role intensities than patentable IP: this is an 
issue that could be considered when drafting guidelines for funding implementation and for reporting of inventor roles.

Thirdly, university administrators should be aware of the fact that academic inventors may enact different types of roles and different role intensities throughout an innovation process, not only based on the IPR ownership system of a university, but also based on the specific IP nature of a particular invention. Consequently, more attention should be paid to IP nature when deciding forms and levels of university support, because IP nature might be a relevant factor that may per se influence the roles of academic inventors.

All in all, the main focus of policy on IPR ownership could be supplemented with a focus on IP nature. In particular, policymakers should consider that nonpatentable innovations can be more difficult to exploit and commercialise and could benefit from high inventor involvement and tailored support to inventors. Further, if patentable innovations are assigned priority in evaluations and support, for instance, by focusing on counting patents, the existing policies might not provide optimal conditions for the exploitation of non-patentable innovations, which might be equally important in providing value to the society.

\section{Acknowledgments}

A draft version of this manuscript was presented at a Scancor Seminar at Stanford University in June 2015. We appreciate the comments and suggestions of the Scancor scholars. We also thank several colleagues for comments and feedback. We acknowledge financial support from three funders: The Medical Faculty at Uppsala University, U-CARE research program at Uppsala University and Anna Maria Lundin's Grant Foundation.

\section{References}

Alam, I (2002). An exploratory investigation of user involvement in new service development. Journal of the Academy of Marketing Science, 30(3), 250-261. https://doi. org/10.1177/0092070302303006.

Andersson, G, J Bergström, F Holländare, P Carlbring, V Kaldo and L Ekselius (2005). Internet-based self-help for depression: Randomised controlled trial. The British Journal of Psychiatry, 187(5), 456-461. https://doi.org/10.1192/bjp.187.5.456.

Anton, JJ and DA Yao (1994). Expropriation and inventions: Appropriable rents in the absence of property rights. The American Economic Review, 84(1), 190-209.

Arora, A and A Gambardella (2010). Ideas for rent: An overview of markets for technology. Industrial and Corporate Change, 19(3), 775-803. https://doi.org/10.1093/ icc/dtq022. 
Arrow, K (1962). Economic welfare and the allocation of resources for invention. In The Rate and Direction of Inventive Activity, R Nelson (Ed.), pp. 609-626. Princeton, NJ: Princeton University Press.

Artz, KW, PM Norman, DE Hatfield and LB Cardinal (2010). A longitudinal study of the impact of R\&D, patents, and product innovation on firm performance. Journal of Product Innovation Management, 27(5), 725-740. https://doi.org/10.1111/j.15405885.2010.00747.x.

Attridge, J (2007). Innovation models in the biopharmaceutical sector. International Journal of Innovation Management, 11(2), 215-243. https://doi.org/10.1142/ S1363919607001746.

Atun, RA and D Sheridan (2007). Editorial: Innovation in health care: The engine of technological advances. International Journal of Innovation Management, 11(2), v-x. https://doi.org/10.1142/S1363919607001692.

Azoulay, P, W Ding and T Stuart (2007). The determinants of faculty patenting behavior: Demographics or opportunities? Journal of Economic Behavior \& Organization, 63(4), 599-623. https://doi.org/10.1016/j.jebo.2006.05.015.

Barki, H and J Hartwick (1994). Measuring user participation, user involvement, and user attitude. MIS Quarterly, 18(1), 59-82. https://doi.org/10.2307/249610.

Bercovitz, J and M Feldman (2008). Academic entrepreneurs: Organizational change at the individual level. Organization Science, 19(1), 69-89. https://doi.org/10.1287/ orsc. 1070.0295 .

Boehm, DN and T Hogan (2014). "A jack of all trades": The role of PIs in the establishment and management of collaborative networks in scientific knowledge commercialisation. The Journal of Technology Transfer, 39(1), 134-149. https://doi.org/ 10.1007/s10961-012-9273-8.

Braunerhjelm, P and R Svensson (2010). The inventor's role: Was Schumpeter right? Journal of Evolutionary Economics, 20(3), 413-444. https://doi.org/10.1007/s00191009-0157-5.

Breschi, S, F Lissoni and F Montobbio (2007). The scientific productivity of academic inventors: New evidence from Italian data. Economics of Innovation and New Technology, 16(2), 101-118. https://doi.org/10.1080/10438590600982830.

Carayol, N (2007). Academic incentives, research organization and patenting at a large French university. Economics of Innovation and New Technology, 16(2), 119-138. https://doi.org/10.1080/10438590600982855.

Clancy, MS and G Moschini (2013). Incentives for innovation: Patents, prizes, and research contracts. Applied Economic Perspectives and Policy, 35(2), 206-241. https://doi.org/10.1093/aepp/ppt012.

Clarysse, B and N Moray (2004). A process study of entrepreneurial team formation: The case of a research-based spin-off. Journal of Business Venturing, 19(1), 55-79.

Clarysse, B, V Tartari and A Salter (2011). The impact of entrepreneurial capacity, experience and organizational support on academic entrepreneurship. Research Policy, 40(8), 1084-1093. https://doi.org/10.1016/j.respol.2011.05.010. 
Colyvas, J, M Crow, A Gelijns, R Mazzoleni, RR Nelson, N Rosenberg and BN Sampat (2002). How do university inventions get into practice? Management Science, 48(1), 61-72. https://doi.org/10.1287/mnsc.48.1.61.14272.

Crespi, GA, A Geuna and B Verspagen (2006). University IPRs and knowledge transfer. Is the IPR ownership model more efficient? SPRU Electronic Working Paper Series, 154, 1-31.

Cunningham, J, P O'Reilly, B Dolan, C O'Kane and V Mangematin (2016). Publicly funded principal investigators allocation of time for public sector entrepreneurship activities. Economia e Politica, 43(4), 383-408. https://doi.org/10.1007/s40812-0160054-5.

Cunningham, J, P O'Reilly and C O'Kane (2015). Managerial challenges of publicly funded principal investigators. International Journal of Technology Management, 68(3-4), 176-201. https://dx.doi.org/10.1504/IJTM.2015.069669.

Denrell, J (2005). Selection bias and the perils of benchmarking. Harvard Business Review, 83(4), 114-119.

Dietz, JS and B Bozeman (2005). Academic careers, patents, and productivity: Industry experience as scientific and technical human capital. Research Policy, 34(3), 349-367. https://doi.org/10.1016/j.respol.2005.01.008.

Ding, WW, F Murray and TE Stuart (2006). Gender differences in patenting in the academic life sciences. Science, 313(5787), 665-667. http://doi.org/10.1126/science.1124832.

Djokovic, D and V Souitaris (2008). Spinouts from academic institutions: A literature review with suggestions for further research. The Journal of Technology Transfer, 33(3), 225-247. https://doi.org/10.1007/s10961-006-9000-4.

Doll, WJ and G Torkzadeh (1989). A discrepancy model of end-user computing involvement. Management Science, 35(10), 1151-1171. https://doi.org/10.1287/mnsc.35.10.1151.

Eisenhardt, KM (1989). Building theories from case study research. Academy of Management Review, 14(4), 532-550. https://doi.org/10.5465/AMR.1989.4308385.

Etzkowitz, H and L Leydesdorff (2000). The dynamics of innovation: From national systems and "mode 2" to a triple helix of university-industry-government relations. Research Policy, 29(2), 109-123. https://doi.org/10.1016/S0048-7333(99)00055-4.

Farnstrand Damsgaard, E and MC Thursby (2013). University entrepreneurship and professor privilege. Industrial and Corporate Change, 22(1), 183-218. https://doi. org/10.1093/icc/dts047.

Feller, I and M Feldman (2010). The commercialization of academic patents: Black boxes, pipelines, and rubik's cubes. The Journal of Technology Transfer, 35(6), 597-616. https://doi.org/10.1007/s10961-009-9123-5.

Franz, CR and D Robey (1986). Organizational context, user involvement, and the usefulness of information systems. Decision Sciences, 17(3), 329-356. https://doi.org/ 10.1111/j.1540-5915.1986.tb00230.x.

Friedman, J and J Silberman (2003). University technology transfer: Do incentives, management, and location matter? The Journal of Technology Transfer, 28(1), 17-30. https://doi.org/10.1023/A:1021674618658. 
Garber, AM, CI Jones and P Romer (2006). Insurance and incentives for medical innovation. Forum for Health Economics and Policy, 9(2), 1-27. https://doi.org/10.2202/ 1558-9544.1006.

Geuna, A and F Rossi (2011). Changes to university IPR regulations in Europe and the impact on academic patenting. Research Policy, 40(8), 1068-1076. https://doi.org/ 10.1016/j.respol.2011.05.008.

Goldfarb, B and M Henrekson (2003). Bottom-up versus top-down policies towards the commercialization of university intellectual property. Research Policy, 32(4), 639-658. https://doi.org/10.1016/S0048-7333(02)00034-3.

Grimpe, C and H Fier (2010). Informal university technology transfer: A comparison between the United States and Germany. The Journal of Technology Transfer, 35(6), 637-650. https://doi.org/10.1007/s10961-009-9140-4.

Gulbrandsen, M and J Smeby (2005). Industry funding and university professors' research performance. Research Policy, 34(6), 932-950. https://doi.org/10.1016/j. respol.2005.05.004.

Haeussler, C and JA Colyvas (2011). Breaking the ivory tower: Academic entrepreneurship in the life sciences in UK and Germany. Research Policy, 40(1), 41-54. https:// doi.org/10.1016/j.respol.2010.09.012.

Håkansson, H and A Waluszewski (2007). Knowledge and Innovation in Business and Industry. The Importance of Using Others. London: Routledge.

Hayter, CS (2011). In search of the profit-maximizing actor: Motivations and definitions of success from nascent academic entrepreneurs. The Journal of Technology Transfer, 36(3), 340-352.

Hellmann, T (2007). The role of patents for bridging the science to market gap. Journal of Economic Behavior and Organization, 63(4), 624-647. https://doi.org/10.1016/j. jebo.2006.05.013.

Herstatt, C and E von Hippel (1992). From experience: Developing new product concepts via the lead user method: A case study in a "low-tech" field. Journal of Product Innovation Management, 9(3), 213-221. https://doi.org/10.1111/15405885.930213.

Ives, B and MH Olson (1984). User involvement and MIS success: A review of research. Management Science, 30(5), 586-603. https://doi.org/10.1287/mnsc.30.5.586.

Jensen, R and M Thursby (2001). Proofs and prototypes for sale: The licensing of university inventions. American Economic Review, 91(1), 240-259.

Kennedy, A, D Reeves, P Bower, V Lee, E Middleton, G Richardson, C Gardner, C Gately and A Rogers (2007). The effectiveness and cost effectiveness of a national lay-led self care support programme for patients with long-term conditions: Apragmatic randomised controlled trial. Journal of Epidemiology and Community Health, 61(3), 254-261. https://doi.org/10.1136/jech.2006.053538.

Kenney, M and D Patton (2009). Reconsidering the Bayh-Dole Act and the current university invention ownership model. Research Policy, 38(9), 1407-1422. https:// doi.org/10.1016/j.respol.2009.07.007. 
Kenney, M and D Patton (2011). Does inventor ownership encourage university researchderived entrepreneurship? A six university comparison. Research Policy, 40(8), 1100-1112. https://doi.org/10.1016/j.respol.2011.05.012.

Kenney, M and D Patton (2012). Bayh-Dole and alternative university technology transfer regimes. In Knowledge Perspectives of New Product Development: A Comparative Approach, DG Assimakopoulos, EG Carayannis and R Dossani (eds.), pp. 253-268. New York, NY: Springer.

Kidwell, D (2014). Navigating the role of the principal investigator: A comparison of four cases. Journal of Technology Transfer, 39(1), 33-51.

Klofsten, M and D Jones-Evans (2000). Comparing academic entrepreneurship in Europe - The case of Sweden and Ireland. Small Business Economics, 14(4), 299-309.

Krabel, S and P Mueller (2009). What drives scientists to start their own company? Research Policy, 38(6), 947-956. https://doi.org/10.1016/j.respol.2009.02.005.

LeFort, SM, K Gray-Donald, KM Rowat and ME Jeans (1998). Randomized controlled trial of a community-based psychoeducation program for the self-management of chronic pain. Pain, 74(2-3), 297-306. https://doi.org/10.1016/S0304-3959(97)00190-5.

Lindelöf, P (2011). Formal institutional contexts as ownership of intellectual property rights and their implications for the organization of commercialization for innovations at universities - Comparative data from Sweden and the United Kingdom. International Journal of Innovation Management, 15(5), 1069-1092. https://doi.org/ 10.1142/S1363919611003611.

Lissoni, F, P Lotz, J Schovsbo and A Treccani (2009). Academic patenting and the professor's privilege: Evidence on Denmark from the KEINS database. Science and Public Policy, 36(8), 595-607. https://doi.org/10.3152/030234209X475443.

Litan, RE, L Mitchell and EJ Reedy (2008). Commercializing university innovations: Alternative approaches. In Knowledge Perspectives of New Product Development: A Comparative Approach, Vol. 8, AB Jaffe, J Lerner and S Stern (eds.), pp. 31-57. Chicago, IL: University of Chicago Press.

Lockett, A and M Wright (2005). Resources, capabilities, risk capital and the creation of university spin-out companies. Research Policy, 34(7), 1043-1057. https://doi.org/ 10.1016/j.respol.2005.05.006.

Lorig, KR, PL Ritter, DD Laurent and K Plant (2006). Internet-based chronic disease selfmanagement: A randomized trial. Medical Care, 44(11), 964-971. https://doi.org/ 10.1097/01.mlr.0000233678.80203.c1.

Lorig, KR, PL Ritter, A Dost, K Plant, DD Laurent and I McNeil (2008). The expert patients programme online, a 1-year study of an internet-based self-management programme for people with long-term conditions. Chronic Illness, 4(4), 247-256. https://doi.org/10.1177/1742395308098886.

Lorig, K, PL Ritter, C Pifer and P Werner (2014). Effectiveness of the chronic disease selfmanagement program for persons with a serious mental illness: A translation study. Community Mental Health Journal, 50(1), 96-103. https://doi.org/10.1007/s10597013-9615-5. 
Mangematin, V, P O'Reilly and J Cunningham (2014). PIs as boundary spanners, science and market shapers. The Journal of Technology Transfer, 39, 1-10. https://doi.org/ 10.1007/s10961-012-9270-y.

Markman, GD, PT Gianiodis, PH Phan and DB Balkin (2005). Innovation speed: Transferring university technology to market. Research Policy, 34(7), 1058-1075. https://doi.org/10.1016/j.respol.2005.05.007.

Merrill, SA and A-M Mazza (eds.) (2011). Managing University Intellectual Property in the Public Interest. Washington, D.C.: The National Academy Press.

Mowery, DC, RR Nelson, BN Sampat and AA Ziedonis (2001). The growth of patenting and licensing by U.S. universities: An assessment of the effects of the Bayh-Dole act of 1980. Research Policy, 30(1), 99-119. https://doi.org/10.1016/S0048-7333(99) 00100-6.

Mowery, DC and BN Sampat (2005). The Bayh-Dole Act of 1980 and university-industry technology transfer: A model for other OECD governments? In Essays in Honor of Edwin Mansfield: The Economics of R\&D, Innovation, and Technological Change, AN Link and FM Scherer (eds.), pp. 233-245. New York, NY: Springer.

Murray, F (2004). The role of academic inventors in entrepreneurial firms: Sharing the laboratory life. Research Policy, 33(4), 643-659. https://doi.org/10.1016/j.respol.2004.01.013.

Murray, F and S Stern (2007). Do formal intellectual property rights hinder the free flow of scientific knowledge? Journal of Economic Behavior and Organization, 63(4), 648-687. https://doi.org/10.1016/j.jebo.2006.05.017.

OECD (2003). Turning Science into Business: Patenting and Licensing at Public Research Organisations. Paris: OECD.

Owen-Smith, J and WW Powell (2001). Careers and contradictions: Faculty responses to the transformation of knowledge and its uses in the life sciences. Research in the Sociology of Work, 10, 109-140.

Patton, MQ (2002). Qualitative Research and Evaluation Methods, 3rd edn. Thousand Oaks, CA: Sage.

Powell, WW, J Owen-Smith and JA Colyvas (2007). Innovaton and emulation: Lessons from American universities in selling private rights to public knowledge. Minerva, 45(2), 121-142. https://doi.org/10.1007/s11024-007-9034-2.

Pressman, L, R Burgess, RM Cook-Deegan, SJ McCormack, I Nami-Wolk, M Soucy and L Walters (2006). The licensing of DNA patents by US academic institutions: An empirical survey. Nature Biotechnology, 24, 31-39. https://doi.org/10.1038/nbt0106-31.

Rasmussen, E, Ø Moen and M Gulbrandsen (2006). Initiatives to promote commercialization of university knowledge. Technovation, 26(4), 518-533. https://doi.org/ 10.1016/j.technovation.2004.11.005.

Robey, D, DL Farrow and CR Franz (1989). Group process and conflict in system development. Management Science, 35(10), 1172-1191. https://doi.org/10.1287/ mnsc.35.10.1172.

Rothaermel, FT, SD Agung and L Jiang (2007). University entrepreneurship: A taxonomy of the literature. Industrial and Corporate Change, 16(4), 691-791. https://doi.org/ 10.1093/icc/dtm023. 
Rouleau, L (2005). Micro-practices of strategic sensemaking and sensegiving: How middle managers interpret and sell change every day. Journal of Management Studies, 42(7), 1413-1441. https://doi.org/10.1111/j.1467-6486.2005.00549.x.

Rycroft-Malone, J (2004). The PARIHS framework - A framework for guiding the implementation of evidence-based practice. Journal of Nursing Care Quality, 19(4), 297-304.

Scotchmer, S (2004). Innovation and Incentives. Cambridge, MA: MIT Press.

Siegel, DS, D Waldman and A Link (2003). Assessing the impact of organizational practices on the relative productivity of university technology transfer offices: An exploratory study. Research Policy, 32(1), 27-48. https://doi.org/10.1016/S00487333(01)00196-2.

Siegel, DS, DA Waldman, LE Atwater and AN Link (2004). Toward a model of the effective transfer of scientific knowledge from academicians to practitioners: Qualitative evidence from the commercialization of university technologies. Journal of Engineering and Technology Management, 21(1-2), 115-142. https://doi.org/ 10.1016/j.jengtecman.2003.12.006.

Smets, M, P Jarzabkowski, GT Burke and P Spee (2015). Reinsurance trading in Lloyd's of London: Balancing conflicting-yet-complementary logics in practice. Academy of Management Journal, 58(3), 932-970.

Smith Hughes, S (2001). Making dollars out of DNA: The first major patent in biotechnology and the commercialization of molecular biology. Isis, 92(3), 541-575.

Stephan, P, S Gurmu and A Sumell (2007). Who's patenting in the university? Evidence from the survey of doctorate recipients. Economics of Innovation and New Technology, 16(2), 71-99. https://doi.org/10.1080/10438590600982806.

Stuart, TE and WW Ding (2006). When do scientists become entrepreneurs? The social structural antecedents of commercial activity in the academic life sciences. American Journal of Sociology, 112(1), 97-144. https://doi.org/10.1086/502691.

Thorburn, L (2000). Knowledge management, research spinoffs and commercialization of R\&D in Australia. Asia Pacific Journal of Management, 17(2), 257-275. https://doi. org/10.1023/A:1015861625956.

Thursby, JG, R Jensen and MC Thursby (2001). Objectives, characteristics and outcomes of university licensing: A survey of major U.S. universities. The Journal of Technology Transfer, 26(1), 59-72. https://doi.org/10.1023/A:1007884111883.

Thursby, JG and MC Thursby (2007). University licensing. Oxford Review of Economic Policy, 23(4), 620-639. https://doi.org/10.1093/icb/grm031.

Titov, N (2007). Status of computerized cognitive behavioural therapy for adults. The Australian and New Zealand Journal of Psychiatry, 41(2), 95-114.

Van de Ven, AH, DE Polley, R Garud and S Venkataraman (1999). The Innovation Journey. New York, NY: Oxford University Press.

Van Looy, B, J Callaert and K Debackere (2006). Publication and patent behavior of academic researchers: Conflicting, reinforcing or merely co-existing? Research Policy, 35(4), 596-608. https://doi.org/10.1016/j.respol.2006.02.003. 
von Krogh, G, K Ichijo and I Nonaka (2000). Enabling Knowledge Creation: How to Unlock the Mystery of Tacit Knowledge and Release the Power of Innovation. New York, NY: Oxford University Press.

von Proff, S, G Buenstorf and M Hummel (2012). University patenting in Germany before and after 2002: What role did the professors' privilege play? Industry and Innovation, 19(1), 23-44. https://doi.org/10.1080/13662716.2012.649060.

Willoughby, KW (2013). What impact does intellectual property have on the business performance of technology firms? International Journal of Intellectual Property Management, 6(4), 316-338. https://doi.org/10.1504/IJIPM.2013.057634.

Wright, M, B Clarysse, A Lockett and M Knockaert (2008). Mid-range universities' linkages with industry: Knowledge types and the role of intermediaries. Research Policy, 37(8), 1205-1223. https://doi.org/10.1016/j.respol.2008.04.021.

Yin, RK (2003). Case Study Research: Design and Methods, 3rd edn. Thousand Oaks, CA: Sage.

Zetterqvist, K, J Maanmies, L Ström and G Andersson (2003). Randomized controlled trial of internet-based stress management. Cognitive Behaviour Therapy, 32(3), 151-160.

Zucker, LG, MR Darby and JS Armstrong (2002). Commercializing knowledge: University science, knowledge capture, and firm performance in biotechnology. Management Science, 48(1), 138-153. https://doi.org/10.1287/mnsc.48.1.138.14274. 